\title{
A Fast and Accurate Analytical Method for Parameter Determination of a Photovoltaic System Based on Manufacturer's Data
}

\author{
Robinson Ndegwa $\mathbb{D}^{1},{ }^{1}$ Justus Simiyu, ${ }^{1}$ Elijah Ayieta, ${ }^{1}$ and Nicodemus Odero ${ }^{2}{ }^{2}$ \\ ${ }^{1}$ Department of Physics, University of Nairobi, P.O. Box 30197-00100, Nairobi, Kenya \\ ${ }^{2}$ Department of Electrical and Electronic Engineering, Machakos University, P.O. Box 136 90100, Machakos, Kenya
}

Correspondence should be addressed to Robinson Ndegwa; ndegwarg@uonbi.ac.ke

Received 3 January 2020; Accepted 24 April 2020; Published 15 May 2020

Academic Editor: Shuhui Li

Copyright (c) 2020 Robinson Ndegwa et al. This is an open access article distributed under the Creative Commons Attribution License, which permits unrestricted use, distribution, and reproduction in any medium, provided the original work is properly cited.

\begin{abstract}
Modeling and simulation of a photovoltaic solar system play a significant role in understanding its behavior in various environmental conditions. Utilization of the datasheet information in modeling and simulation of the PV system correlates the experimental data and the theory that instigate the mathematical predictions of an actual system. A single-diode model gives a simple, fast, and straightforward way of depicting the PV system performance. We have developed a new approach of determining the five unknown parameters of a single-diode model using manufacturer's data at three main points: the open circuit point (OCP), short circuit point (SCP), and the maximum power point (MPP) of the IV and PV curves. The ideality factor $(A)$ and the diode saturation current $\left(I_{o}\right)$ are the key unknown parameters that greatly affect the reduplication of the three main points. The purpose of this study is to evaluate the ideality factor using simple calculation procedure starting from its optimal value $\left(A_{o}\right)$ and other values within the proximity of $A_{o}$. The optimal value is obtained by assumptions of negligible series resistance $\left(R_{s}\right)$ and very large shunt resistance $\left(R_{\mathrm{sh}}\right)$. Therefore, the choice of the other ideality factors in the neighborhood of its optimal value gives rise to different values of $R_{s}, R_{\mathrm{sh}}$, and $I_{\mathrm{ph}}$ that are more realistic in an experimental setup. Positive values of $R_{\mathrm{sh}}$ and $R_{s}$ have been iteratively obtained by utilizing data at maximum power point combined with open and short circuit data. The five unknown parameters have been determined in the proximity of $A_{o}$ and have been used to plot the PV curve with accuracy and precision of less than $0.5 \%$ error of maximum power and less than $0.1 \%$ error of $V_{\text {oc }}$ of manufacturer's data. The proposed method has been implemented using fast, simple, and accurate procedures using GNU Octave programming software to calculate $A_{o}, I_{o}, R_{s}, R_{\mathrm{sh}}$, and $I_{\mathrm{ph}}$ and to execute both $R_{s}-R_{\mathrm{sh}}$ and PV characteristic equations of BP3235T, KC200GT, BP-SX 150, and MSX60 PV modules. The reduced steps employed in the algorithm improve execution speed, thereby reducing the computation time.
\end{abstract}

\section{Introduction}

Single- and double-diode PV models have been widely used for evaluation and analysis of electrical characteristics for photovoltaic (PV) solar modules [1-3]. Several authors [4-8] have reviewed the advantages and drawbacks of both models and compared their accuracy in replicating the experimental IV and PV curves. Comparative study of the two models showed a trade-off between accuracy and computation time [9]. The double-diode model gives better profiling of the PV modules but requires complex computation procedure in order to extract its seven unknown parameters [10, 11]. However, improved approaches for calculating unknown parameters using seven [12], six [13], five [14], and four parameters [15] for the double-diode models have also been studied. These methods utilize numerical algorithms such as particle swarm optimization or the Newton-Raphson method that requires large amount of data and several mathematical manipulations to evaluate the unknown parameters. Therefore, the single-diode model remains a method of choice where quick and simplified analyses are required for design of maximum power point tracking (MPPT). 
A single-diode model has five unknown parameters $(A$, $I_{o}, I_{\mathrm{ph}}, R_{s}$, and $\left.R_{\mathrm{sh}}\right)$ that must be determined to obtain the best solution of the current-voltage equation [16]. Several approaches have been discussed in the literature for determination of the correct values of these five parameters $[17,18]$. The simplest model that reduces the number of unknown parameters to three $\left(A, I_{o}\right.$, and $\left.I_{\mathrm{ph}}\right)$ is a singleexponential diode equivalent circuit without any resistance [19-21]. Ignoring the series and shunt resistances gives inaccurate evaluation of the PV module and fails to account for the loss of power due to electrical contacts, base region, and the front layer [22]. A better approach based on four parameters incorporates a series resistance and omits the shunt resistance [23-25]. The five-parameter model gives the best solutions since it accounts for the effect of power losses due to parasitic series and shunt resistances that are embedded in the solar module as a result of fabrication defects [26, 27].

The five-parameter single-diode model is based on a Shockley diode equivalent circuit with series and parallel resistances and is defined by a transcendental equation that cannot be solved explicitly. Several procedures have been developed for evaluation and determination of the lumped parameters, namely, ideality factor $(A)$, saturation current $\left(I_{o}\right)$, photocurrent $\left(I_{\mathrm{ph}}\right)$, and shunt $\left(R_{\mathrm{sh}}\right)$ and series $\left(R_{s}\right)$ resistances, using IV characteristic [8]. Experimental data or information available from manufacturer's datasheet is usually utilized in order to derive the necessary nonlinear equations for extraction of the unknown parameters by considering three crucial points at short circuit current, open circuit voltage, and maximum power point of an IV curve [28]. Experimental procedures are expensive and require more time for setup, data collection, and analysis [29]. Nevertheless, evaluation of the five parameters using manufacturer's data has become more popular since the information about the three critical points is readily available at STC and NOCT for module with IEC standards [30-32]. Different approaches have been proposed for extraction of these unknown parameters depending on which parameter is perturbed first, either $R_{s}$ or $A$. Traditionally, the straightforward way of getting the five parameters has been based on five nonlinear equations selected from the three critical points and determining the $R_{S}$ and $R_{\text {sh }}$ from the reciprocal of IV slopes at these points $[33,34]$. Computer software has been exploited to solve these equations using Lambert W function $[35,36]$, nonlinear least square (NLS) [37], and Newton-Raphson algorithms [38, 39]. These techniques are comprehensive methods with good accuracy and fast convergence but their main drawbacks are complex implementation procedures and relatively low calculation speed that require more computing power.

Recent advances in computing technology has led to application of evolutionary computation techniques inspired by biological evolution and chemistry/physics-based, swarming-based, and hybridization-based algorithms for extraction of the unknown parameters for single-, double-, or triple-diode models [40]. These soft-computing techniques are problem solvers using trial and error metaheuristic or stochastic optimization procedures such as pattern search (PS) [41], genetic algorithm (GA) [42], simulated annealing (SA) $[43,44]$, particle swarm optimization [45, 46], artificial fish swarm algorithm (AFSA) [47], fuzzy logic [48], and artificial neural networks (ANNs) [49-51]. These methods have disadvantages, either in terms of sophistication and accuracy or in terms of convergence and speed of execution.

Fast and simplified approaches that calculate all model parameters for the single-diode model of the photovoltaic system directly rely on careful evaluation of the underlying analytical and numerical algorithms [52, 53]. Straightforward analytical methods for describing the parameters of PV models are heavily dependent on nonlinear explicit formulas using $I_{\mathrm{sc}}, I_{\mathrm{mpp}}, V_{\mathrm{mpp}}$, and $V_{\mathrm{oc}}$ data in the PV panel datasheet [54]. The simplest and comprehensive approach assumes arbitrary value of ideality factor and determines other parameters by adjusting the curve at $I_{\mathrm{sc}}, P_{\mathrm{mpp}}$, and $V_{\mathrm{oc}}$ points [55]. An ideal diode has an ideality factor of unity. However, an appropriate and actual diode for modeling PV system has ideality factor values ranging from one to two [56]. An accurate and fast convergence method of extracting the unknown parameters by first analyzing the ideality factor and setting it as the primary parameter and obtaining the loss resistance through a repetitive process was reported in [57]. The authors used a protracted method to arrive at a control signal that was based on the series resistance value. In this paper, we present a novel analytical method for determining the single-diode model parameters directly from the manufacturer's datasheet using explicit equations.

\section{A Single-Diode Equivalent Circuit}

A single-diode equivalent circuit shown in Figure 1 can be mathematically modeled using equation (1) [16]. A Shockley's diode is connected in parallel to the current source and shunt resistor and in series to $R_{s}$ and the load.

$$
I=I_{\mathrm{ph}}+I_{o}-I_{o} \exp \frac{q\left(V+I R_{s}\right)}{A N_{s} k T}-\frac{V}{R_{\mathrm{sh}}}-\frac{I R_{s}}{R_{\mathrm{sh}}},
$$

where $I$ is module output current in amperes (A), $V$ is module output voltage in volts $(\mathrm{V}), q$ is charge of an electron $=1.602176634 \times 10^{-19} \mathrm{C}, k$ is Boltzmann's constant $=$ $1.380649 \times 10^{-23} \cdot \mathrm{m}^{2} \mathrm{~s}^{-2} \cdot \mathrm{kgK}^{-1}$, and $T_{\mathrm{STC}}$ is standard temperature $=298.15 \mathrm{~K}$ at STC

\section{Mathematical Modeling of a PV System Using Three Critical Points and Their Respective Slopes of an IV Curve}

Equation (1) can be evaluated by analyzing the open circuit, short circuit, and the maximum power points whose data are usually available from datasheets.

At short circuit, $I=I_{\mathrm{sc}}, V=O$.

In Figure 1, a short circuit without the load gives zero voltage and current $\mathrm{I} \approx I_{\mathrm{sc}}$ that depend on $I_{\mathrm{ph}}, A, I_{o}, T, R_{s}$, and $R_{\mathrm{sh}}[16,58]$. Therefore, we can rewrite equation (1) as 


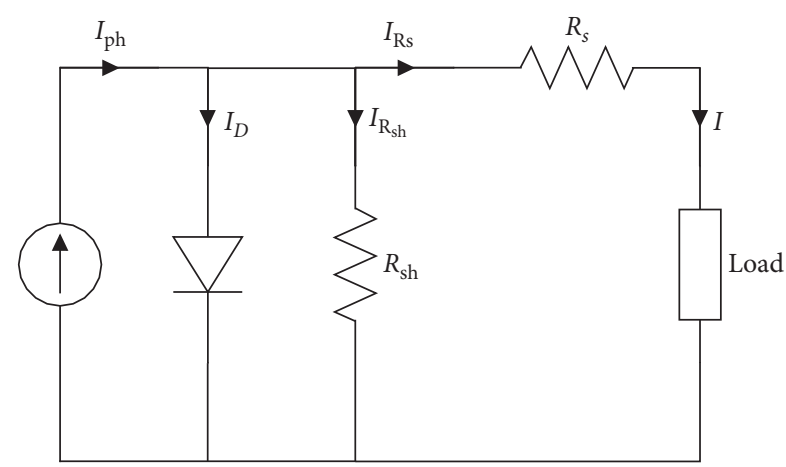

FIGURE 1: A single-diode equivalent circuit.

$$
I_{\mathrm{sc}}=I_{\mathrm{ph}}+I_{o}-I_{o} \exp \left(\frac{I_{\mathrm{sc}} R_{s}}{A N_{s} V_{t}}\right)-\frac{I_{\mathrm{sc}} R_{s}}{R_{\mathrm{sh}}},
$$

where $V_{t}=k T / q=0.0256796347$ is the thermal voltage.

At open circuit, $I=O, V=V_{\text {oc }}$; likewise, at open circuit, we can also rearrange equation (1) to get

$$
I_{\mathrm{ph}}=I_{o}\left(\frac{V_{\mathrm{oc}}}{A N_{s} V_{t}}\right)-I_{o}+\frac{V_{\mathrm{oc}}}{R_{\mathrm{sh}}} .
$$

For fast convergence, equation (3) can be expressed logarithmically as

$$
\ln \left(I_{\mathrm{ph}}+I_{o}-\frac{V_{\mathrm{oc}}}{R_{\mathrm{sh}}}\right)-\ln \left(I_{o}\right)=\frac{V_{\mathrm{oc}}}{A N_{s} V_{t}}
$$

At maximum power point, $I=I_{\mathrm{mpp}}, V=V_{\mathrm{mpp}}$; we can similarly replace $I=I_{\mathrm{mpp}}, V=V_{\mathrm{mpp}}$ in equation (1) to obtain

$$
I_{\mathrm{mpp}}=I_{\mathrm{ph}}+I_{o}-I_{o} \exp \left(\frac{V_{\mathrm{mpp}}+I_{\mathrm{mpp}} R_{s}}{A N_{s} V_{t}}\right)-\frac{V_{\mathrm{mpp}}+I_{\mathrm{mpp}} R_{s}}{R_{\mathrm{sh}}} \text {. }
$$

This can also be evaluated as

$\ln \left(I_{\mathrm{ph}}+I_{o}-I_{\mathrm{mpp}}-\frac{V_{\mathrm{mpp}}+I_{\mathrm{mpp}} R_{s}}{R_{\mathrm{sh}}}\right)-\ln \left(I_{o}\right)=\frac{V_{\mathrm{mpp}}+I_{\mathrm{mpp}} R_{s}}{A N_{s} V_{t}}$.

Subtracting equations (4) and (6) yields

$\ln \left(\frac{I_{\mathrm{ph}}+I_{o}-V_{\mathrm{oc}} / R_{\mathrm{sh}}}{I_{\mathrm{ph}}+I_{o}-I_{\mathrm{mpp}}-\left(V_{\mathrm{mpp}}+I_{\mathrm{mpp}} R_{s}\right) / R_{\mathrm{sh}}}\right)=\frac{V_{\mathrm{oc}}-V_{\mathrm{mpp}}-I_{\mathrm{mpp}} R_{s}}{A N_{s} V_{t}}$.

This reduces to the five-parameter mathematical model that can be written as

$$
A=\frac{V_{\mathrm{oc}}-V_{\mathrm{mpp}}-I_{\mathrm{mpp}} R_{s}}{N_{s} V_{t}\left[\ln \left(I_{\mathrm{ph}}+I_{o}-V_{\mathrm{oc}} / R_{\mathrm{sh}} / I_{\mathrm{ph}}+I_{o}-I_{\mathrm{mpp}}-\left(V_{\mathrm{mpp}}+I_{\mathrm{mpp}} R_{s}\right) / R_{\mathrm{sh}}\right)\right]} .
$$

3.1. Photocurrent $\left(I_{p h}\right)$ Analysis. The photocurrent can be deduced by rearranging equation (2) in order to obtain equation (9) in terms of $A, I_{o}, R_{s}$, and $R_{\mathrm{sh}}$ to get

$$
I_{\mathrm{ph}}=I_{\mathrm{sc}}-I_{o}+I_{o} \exp \left(\frac{I_{\mathrm{sc}} R_{s}}{A N_{s} V_{t}}\right)+\frac{I_{\mathrm{sc}} R_{s}}{R_{\mathrm{sh}}} .
$$

The light-generated current of the PV cell is linearly dependent on the solar irradiance and also varies with the temperature. Therefore, the relationship between photocurrent, temperature, and irradiance can be evaluated using temperature coefficient of $I_{\mathrm{sc}}\left(K_{I}\right)$ as reported in $[38,59,60]$. Thus,

$$
I_{\mathrm{ph}}=\frac{s}{s_{\mathrm{STC}}}\left[I_{\mathrm{phSTC}}+K_{I}\left(T-T_{\mathrm{STC}}\right)\right] \text {, }
$$

where $T$ is the actual temperature in Kelvin, $T_{\text {STC }}$ is the temperature at STC usually $298.15 \mathrm{~K}, s$ is the irradiance on the PV surface, $s_{\text {STC }}$ is the irradiance at STC usually $1000 \mathrm{~W} / \mathrm{m}^{2}$, and $I_{\mathrm{phSTC}}$ is the light-generated current at STC.

3.2. Ideality Factor (A) Analysis. One of the simplest ways of determining the ideality factor is to evaluate its value at standard test conditions (STCs) using data provided in manufacturer's datasheet. Using the information obtainable from the datasheet for $I_{\mathrm{sc}}, I_{\mathrm{mpp}}, V_{\mathrm{mpp}}$, and $V_{\mathrm{oc}}$, the optimal value of ideality factor can be easily deduced from equation
(8) by letting the photocurrent $\left(I_{\mathrm{ph}}\right)$ to be equivalent to short circuit current $\left(I_{\mathrm{sc}}\right)$. We can also assume that $R_{s}$ has minimal resistance value $\left(R_{s} \approx 0\right)$ and $R_{\mathrm{sh}}$ has large resistance value $\left(R_{\mathrm{sh}} \approx \infty\right)$ whose effects can initially be ignored in the equation. These assumptions will be reevaluated later in the following sections to consider the nominal operation parameters, in which Rs and Rsh have other more practical values. Thus, we can evaluate ideality factor as

$$
A=\frac{V_{\mathrm{oc}}-V_{\mathrm{mpp}}}{N_{s} V_{t}}\left[\ln \left(\frac{I_{\mathrm{sc}}+I_{o}}{I_{\mathrm{sc}}+I_{o}-I_{\mathrm{mpp}}}\right)\right]^{-1} .
$$

A closer look at its denominator infers that the logarithm term is greatly influenced by the short circuit current. Therefore, small values of saturation current in microamperes range can be ignored. This gives rise to the optimum value of ideality factor $\left(A_{o}\right)$ that can be expressed as

$$
A_{o}=\frac{V_{\mathrm{oc}}-V_{\mathrm{mpp}}}{N_{s} V_{t}}\left[\ln \left(\frac{I_{\mathrm{sc}}}{I_{\mathrm{sc}}-I_{\mathrm{mpp}}}\right)\right]^{-1} .
$$

Figure 2 illustrates the variation of ideality factor $(A)$ with respect to saturation current for BP3235T, KC200GT, BP-SX 150, and MSX60 PV modules, respectively. The values of $I_{o}$ have been arbitrarily chosen within an acceptable range from 0 to $1 \mathrm{~A}$. According to Figure 2, the ideality factor 


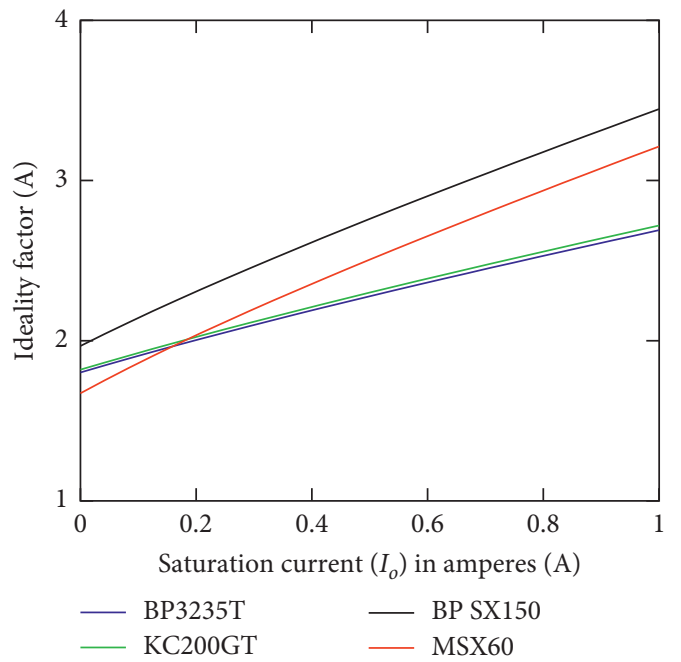

Figure 2: A graph of $A$ vs $I_{o}$ for BP3235T, KC200GT, BP-SX 150, and MSX60 PV modules.

increases as saturation current $\left(I_{o}\right)$ increases and vice versa. The intercept on the $y$-axis represents the values of optimal ideality factor $\left(A_{o}\right)$ and optimal saturation current $\left(I_{\text {oopt }}\right)$ for each respective PV modules provided in Table 1.

The optimum value of the ideality factor $\left(A_{o}\right)$ has been deduced from very low series and high shunt resistances. In order to consider other $R_{s}$ and $R_{\mathrm{sh}}$ resistances that are more realistic and achievable in a practical setup, it is important to consider the ideality factor in the neighborhood of $A_{o}$ such that $1 \leq A \leq A_{o}$ at a constant $I_{o}$. In this work, we have evaluated the effect of ideality factor on $I_{\mathrm{ph}}, R_{s}$, and $R_{\mathrm{sh}}$ by arbitrarily selecting different values of $A$ in the neighborhood of $A_{0}$ as discussed in Sections 3.3 and 3.4.
TABLe 1: PV module data $\left(P_{\mathrm{mpp}}, I_{\mathrm{sc}}, I_{\mathrm{mpp}} V_{\mathrm{oc}}, V_{\mathrm{mpp}}\right.$, and $\left.N_{s}\right)$ at STC.

\begin{tabular}{lcccc}
\hline & \multicolumn{4}{c}{ PV module } \\
Parameters & Solarex & BP-SX & Kyocera & BP3235T \\
& MSX60 & 150 & KC200GT & \\
\hline$P_{\text {mpp }}(\mathrm{W})$ & 60 & 150 & 200 & 235 \\
$I_{\text {sc }}(\mathrm{A})$ & 3.8 & 4.75 & 8.21 & 8.48 \\
$I_{\text {mpp }}(\mathrm{A})$ & 3.5 & 4.35 & 7.61 & 7.89 \\
$V_{\text {oc }}(\mathrm{V})$ & 21.1 & 43.5 & 32.9 & 37.2 \\
$V_{\text {mpp }}(\mathrm{V})$ & 17.1 & 34.5 & 26.3 & 29.8 \\
$N_{s}$ & 36 & 72 & 54 & 60 \\
\hline
\end{tabular}

3.3. Saturation Current $\left(I_{o}\right)$ Analysis. The saturation current appears as a constant at STC in equation (1) and can be calculated by merging two of the three equations that have been derived at the crucial points. Substituting Iph appearing in equation 2 with Iph defined in equation 3 as discussed by the authors in $[52,61]$, the saturation current $\left(I_{o}\right)$ at $I_{\mathrm{sc}}$ and $V_{\mathrm{oc}}$ can be derived as follows:

$$
\left[I_{o}\right]_{I_{\mathrm{sc}}, V_{\mathrm{oc}}}=\frac{I_{\mathrm{sc}} R_{\mathrm{sh}}+I_{\mathrm{sc}} R_{s}-V_{\mathrm{oc}}}{R_{\mathrm{sh}}\left[\exp \left(V_{\mathrm{oc}} / A N_{s} V_{t}\right)-\exp \left(I_{\mathrm{sc}} R_{s} / A N_{s} V_{t}\right)\right]}
$$

Since $I_{o}$ depends on temperature, we can first determine its optimal value at STC by assuming the boundary parameter values for $R_{s} \approx 0$ and $R_{\mathrm{sh}} \approx \infty$. Consequently, we can rewrite equation (13) as

$$
\left[I_{o_{\mathrm{opt}}}\right]_{I_{\mathrm{sc}}, V_{\mathrm{oc}}}=\frac{I_{\mathrm{sc}}}{\left[\exp \left(V_{\mathrm{oc}} / A N_{s} V_{t}\right)\right]}
$$

Similarly, equation (2) can be merged with equation (5) at $I_{\mathrm{sc}}$ and $P_{\mathrm{mpp}}$ to obtain

$$
\left[I_{o}\right]_{I_{\mathrm{sc}}, P_{\mathrm{mpp}}}=\frac{V_{\mathrm{mpp}}+I_{\mathrm{mpp}} R_{\mathrm{sh}}+I_{\mathrm{mpp}} R_{s}-I_{\mathrm{sc}} R_{s}-I_{\mathrm{sc}} R_{\mathrm{sh}}}{R_{s h}\left[\exp \left(I_{\mathrm{sc}} R_{s} / A N_{s} V_{t}\right)-\exp \left(\left(V_{\mathrm{mpp}}+I_{\mathrm{mpp}}\right) R_{s} / A N_{s} V_{t}\right)\right]} .
$$

Returning to $R_{s} \approx 0$ and $R_{\mathrm{sh}} \approx \infty$, equation (15) reduces to

$$
\left[I_{O_{\mathrm{opt}}}\right]_{I_{\mathrm{sc}}, P_{\mathrm{mpp}}}=\frac{I_{\mathrm{sc}}-I_{\mathrm{mpp}}}{\exp \left(V_{\mathrm{mpp}} / A N_{s} V_{t}\right)} \text {. }
$$

Finally, considering equation (3) and (5) at $V_{\mathrm{oc}}$ and $P_{\mathrm{mpp}}$, we can deduce the saturation current as

$$
\left[I_{o}\right]_{V_{\mathrm{oc}}, P_{\mathrm{mpp}}}=\frac{V_{\mathrm{mpp}}-V_{\mathrm{oc}}+I_{\mathrm{mpp}} R_{\mathrm{sh}}+I_{\mathrm{mpp}} R_{s}}{R_{\mathrm{sh}}\left[\exp \left(V_{\mathrm{oc}} / A N_{s} V_{t}\right)-\exp \left(\left(V_{\mathrm{mpp}}+I_{\mathrm{mpp}}\right) R_{s} / A N_{s} V_{t}\right)\right]} .
$$

Again, assuming $R_{s} \approx 0$ and $R_{\mathrm{sh}} \approx \infty$, we can rewrite equation (17) as

$$
\left[I_{O_{\mathrm{opt}}}\right]_{V_{\mathrm{oc}} P_{\mathrm{mpp}}}=\frac{I_{\mathrm{mpp}}}{\left[\exp \left(V_{\mathrm{oc}} / A N_{s} V_{t}\right)-\exp \left(V_{\mathrm{mpp}} / A N_{s} V_{t}\right)\right]} \text {. }
$$

3.3.1. Dependence of the Saturation Current on Irradiance and Temperature. The saturation current is not explicitly dependent on the irradiance, so in the absence of irradiation, the term dark saturation current is used interchangeably with saturation current $[62,63]$. In contrast, the dark saturation current strongly depends on temperature, geo- 
metrical or transport semiconductor parameters, and the intrinsic carrier concentration $[63,64]$. In addition, the intrinsic carrier concentration number depends on the conduction and valence band density of states and on the energy band gap $\left(E_{g}\right)$ of the semiconductor [64].

Therefore, saturation current density for a Schottky junction diode can be expressed using the derivation given in $[63]$ as

$$
J_{o}=D T^{3} \exp \left(\frac{-q E_{g}}{k T}\right)
$$

where $J_{o}$ is the dark saturation current density, $T$ is the actual temperature, $D$ is the diode diffusion factor which is independent of temperature, $k$ is Boltzmann's constant, and $E_{g}$ is the semiconductor's band gap energy $\left(E_{g}=1.12 \mathrm{eV}\right.$ for Si and $1.35 \mathrm{eV}$ for $\mathrm{GaGs})$.

Applying equation (19) to a solar system, the saturation current can be determined using similar approach presented in [65] to get

$$
I_{o}=I_{o_{\mathrm{STC}}}\left[\frac{T}{T_{\mathrm{STC}}}\right]^{3} \exp \frac{q E_{g}}{A N_{s} k}\left[\frac{1}{T_{\mathrm{STC}}}-\frac{1}{T}\right],
$$

where $I_{o_{\text {STC }}}$ is the saturation current at standard test condition.

The saturation current at STC $\left(I_{o_{\mathrm{STC}}}\right)$ can be calculated using either equation (13), (15), or (17). However, these equations depend on $R_{s}, R_{\mathrm{sh}}$, and $A$, which are also unknown parameters that must be determined. Thus, since this new approach takes into account the upper boundary value of the ideality factor $\left(A_{o}\right)$ by assuming minimal series resistance $\left(R_{s} \approx 0\right)$ and large shunt resistance $\left(R_{\mathrm{sh}} \approx \infty\right)$, same assumptions can be used to calculate the optimal saturation current $\left(I_{o_{\text {opt }}}\right)$ at STC using either equation (14), (16), or (18). Therefore, equation (20) can be written as

$$
I_{o}=I_{o_{\text {optSTC }}}\left[\frac{T}{T_{\mathrm{STC}}}\right]^{3} \exp \frac{q E_{g}}{A N_{s} k}\left[\frac{1}{T_{\mathrm{STC}}}-\frac{1}{T}\right] .
$$

3.4. Series Resistance $\left(R_{s}\right)$ and Shunt Resistance $\left(R_{\text {sh }}\right)$ Analysis. The shunt and series resistances have been neglected in calculating the optimal ideality factor in the previous section. However, the maximum power of a solar module can be estimated as the optimal power in the absence of $R_{s}$ and $R_{\mathrm{sh}}$ and the power losses in them. The shunt and series can be evaluated using the combinations of equations derived using the three crucial points and the slopes at either output power at maximum power point or at short circuit point. The following section discusses these different ways of deriving the relationship between $R_{\mathrm{sh}}$ and $R_{s}$.

(i) At maximum power point only: the relationship between $R_{\mathrm{sh}}$ and $R_{s}$ can be evaluated by rearranging equation (5) to get

$R_{\mathrm{sh}}=\frac{V_{\mathrm{mpp}}+I_{\mathrm{mpp}} R_{s}}{I_{\mathrm{ph}}-I_{\mathrm{mpp}}-I_{o}\left(\exp \left(\left(V_{\mathrm{mpp}}+I_{\mathrm{mpp}} R_{s}\right) /\left(A N_{s} V_{t}\right)\right)-1\right)}$.

(ii) Combining the equations defining the short circuit point at $\left(I_{\mathrm{sc}}\right)$ and open circuit point at $\left(V_{\mathrm{oc}}\right)$ : equating (3) and (4) correlates $R_{\mathrm{sh}}$ and $R_{s}$ with $I_{\mathrm{sc}}$ and $V_{\mathrm{oc}}$ as follows:

$$
R_{\mathrm{sh}}=\frac{V_{\mathrm{oc}}-I_{\mathrm{sc}} R_{s}}{I_{\mathrm{sc}}+I_{o} \exp \left(I_{\mathrm{sc}} R_{s} / A N_{s} V_{t}\right)-I_{o} \exp \left(\exp V_{\mathrm{oc}} / A N_{s} V_{t}\right)} .
$$

(iii) Combining the equations defining short circuit point at $\left(I_{\mathrm{sc}}\right)$ and maximum power point at $\left(P_{\mathrm{mpp}}\right)$ : this can be done by substituting equation (3) into equation (5) to obtain

$$
R_{\mathrm{sh}}=\frac{V_{\mathrm{mpp}}+I_{\mathrm{mpp}} R_{s}-I_{\mathrm{sc}} R_{s}}{I_{\mathrm{sc}}-I_{\mathrm{mpp}}-I_{o} \exp \left(\left(V_{\mathrm{mpp}}+I_{\mathrm{mpp}} R_{s}\right) / A N_{s} V_{t}\right)+I_{o} \exp \left(\exp I_{\mathrm{sc}} R_{s} / A N_{s} V_{t}\right)} .
$$

Equations (22) and (24) give similar positive $R_{s}$ and $R_{\text {sh }}$ values for ideality factors above $A_{o}$ since they depend on $P_{\mathrm{mpp}}$ and $I_{\mathrm{sc}}$. Equation (23) has unreasonable outcome of $R_{\mathrm{sh}}$ and $R_{s}$ pairs.

(iv) Combining the equations defining open circuit point at $\left(V_{\mathrm{oc}}\right)$ and maximum power point at $\left(P_{\mathrm{mpp}}\right)$ :
The dependence of $R_{\mathrm{sh}}$ on $R_{s}, V_{\mathrm{oc}}$ and $P_{\mathrm{mpp}}$ can be expressed by rearranging equations (4) and (5) to obtain

$$
R_{\mathrm{sh}}=\frac{V_{\mathrm{oc}}-V_{\mathrm{mpp}}-I_{\mathrm{mpp}} R_{s}}{I_{\mathrm{mpp}}+I_{o} \exp \left(\left(V_{\mathrm{mpp}}+I_{\mathrm{mpp}} R_{s}\right) / A N_{s} V_{t}\right)-\exp \left(\exp V_{\mathrm{oc}} / A N_{s} V_{t}\right)} .
$$


(v) Using the derivatives of equation (1) with respect to $V$ at short circuit and open circuit points along with the derivative of $P=I V$ with respect to $\mathrm{V}$ or $\mathrm{I}$ at maximum power point $[16,38,58,66]$ :

Differentiating equation (1) with respect to $\mathrm{V}$ gives

$$
\frac{\partial I}{\partial V}=-\frac{I_{o}}{A N_{s} V_{t}}\left\{\left(1+\frac{\partial I}{\partial V} R_{s}\right) \exp \left(\frac{V+I R_{s}}{A N_{s} V_{t}}\right)-\frac{1}{R_{\mathrm{sh}}}\left(1+\frac{\partial I}{\partial V}\right) R_{s}\right\} .
$$

It has been shown in [67] that the derivative at short circuit point can be approximated as

$$
\left[\frac{\partial I}{\partial V}\right]_{I=I_{\mathrm{sc}}}=-\frac{1}{R_{\mathrm{sh}}}
$$

and at open circuit point, the derivative can be approximated as

$$
\left[\frac{\partial I}{\partial V}\right]_{V=V_{o c}}=-\frac{1}{R_{s}}
$$

At maximum power point, the power derivative with respect to voltage can be evaluated as

$$
\frac{\partial P}{\partial V}=\left(\frac{\partial I}{\partial V}\right) V+I=O
$$

Taking into consideration that $V=V_{\mathrm{mpp}}$ and $I=I_{\mathrm{mpp}}$ at maximum power point, we can rewrite equation (29) as

$$
\begin{aligned}
-\frac{I_{\mathrm{mpp}}}{V_{\mathrm{mpp}}}= & -\frac{I_{o}}{A N_{s} V_{t}}\left\{\left(1-\frac{I_{\mathrm{mpp}}}{V_{\mathrm{mpp}}} R_{s}\right) \exp \left(\frac{V_{\mathrm{mpp}}+I_{\mathrm{mpp}} R_{s}}{A N_{s} V_{t}}\right)\right\} \\
& -\frac{1}{R_{\mathrm{sh}}}\left(1-\frac{I_{\mathrm{mpp}}}{V_{\mathrm{mpp}}} R_{s}\right) .
\end{aligned}
$$

Rearranging equation (30), we can obtain

$$
R_{\mathrm{sh}}=\frac{V_{\mathrm{mpp}}-I_{\mathrm{mpp}} R_{s}}{I_{\mathrm{mpp}}-I_{o} / A N_{s} V_{t}\left(V_{\mathrm{mpp}}-I_{\mathrm{mpp}} R_{s}\right) \exp \left(\left(V_{\mathrm{mpp}}+I_{\mathrm{mpp}} R_{s}\right) / A N_{s} V_{t}\right)}
$$

The four independent equations (22), (24), (25), and (31) that depend on $V_{\mathrm{oc}}, I_{\mathrm{mpp}}$, and $V_{\mathrm{mpp}}$, have four unknown parameters $\left(R_{s}, R_{\mathrm{sh}}, A\right.$, and $\left.I_{o}\right)$ that can be resolved using either Newton-Raphson algorithm [38, 39, 68, 69], nonlinear least square (NLS) algorithm [37], or Lambert W function $[35,36,70]$ algorithm to analytically determine the values of unknown PV model parameters. These methods have different levels of computational complexity, accuracy, convergence, and execution speed [8]. A simplified approach is presented in this work using an iterative algorithm that considers the boundary values of ideality factor and saturation current as discussed in the following section.

3.4.1. Evaluation of $R_{\text {sh }}$ and $R_{s}$ Based on $A$ below $A_{o}$ (Method 1). This paper proposes a robust method of obtaining the unknown parameters of equation (1) by first obtaining the optimal values of the ideality factor using equation (12) and consequently obtaining $I_{o} \approx I_{o_{\mathrm{opt}}}$ based on either equation (14), (16), or (18). The actual ideality factor $(A)$ is arbitrarily chosen in the neighborhood of $A_{o}$ and applied in either equation (25) or (31), which leaves $R_{s}$ and $R_{\mathrm{sh}}$ as the only unknown parameters. Utilization of equations (25) and (31) can be done separately when the values of $A$ are selected above or below $\left(A_{o}\right)$. When applied in equation (25), the values of ideality factor below $A_{o}$ give positive and negative values of $R_{\text {sh }}$ but give negative and unrealistic values for $A_{s}$ above $A_{o}$. The best choice of $R_{s}$ and $R_{\text {sh }}$ pairs should be at positive peak values of $R_{\mathrm{sh}}$. A choice of $R_{s}$ values in steps of $+0.0001 \Omega$ above $R_{s}$ of a positive peak gives $R_{s}$ and $R_{\text {sh }}$ pairs that are more pragmatic. This approach is a departure from the conventional analytical methods reported in $[52,55,58,61]$ that assumes arbitrary values of ideality factor between 1 and 1.5. The optimal saturation current is kept constant when arbitrarily selecting the ideality factor near $A_{o}$. To ensure a fast and an easy way of evaluating $R_{s}$ and $R_{\mathrm{sh}}$, $I_{o}$ in equation (25) can be replaced by $I_{o_{\text {opt }}}$ of equation (14) to get

$$
R_{\mathrm{sh}}=\frac{V_{\mathrm{oc}}-V_{\mathrm{mpp}}-I_{\mathrm{mpp}} R_{s}}{I_{\mathrm{mpp}}+I_{\mathrm{sc}} \exp \left(-V_{\mathrm{oc}} / A_{\mathrm{o}} N_{s} V_{t}\right) \exp \left(\left(V_{\mathrm{mpp}}+I_{\mathrm{mpp}} R_{s}\right) / A N_{s} V_{t}\right)-I_{\mathrm{sc}} \exp \left(-V_{\mathrm{oc}} / A_{\mathrm{o}} N_{s} V_{t}\right) \exp \left(V_{\mathrm{oc}} / A N_{s} V_{t}\right)} .
$$

Equation (32) can be analyzed using a similar approach used in [55], in which an iterative method is employed to obtain the $\left[R_{s}, R_{\mathrm{sh}}\right]$ pair that satisfies equation (33) in which
$P_{\mathrm{mpp}}$ relationship has been derived by replacing $I=I_{\mathrm{mpp}}$ and $V=V_{\mathrm{mpp}}$ in (1) to yield 


$$
\begin{aligned}
P_{\mathrm{mpp}}= & I_{\mathrm{mpp}} V_{\mathrm{mpp}}=V_{\mathrm{mpp}}\left(I_{\mathrm{ph}}+I_{o}-I_{o} \exp \left(\frac{V_{\mathrm{mpp}}+I_{\mathrm{mpp}} R_{s}}{A N_{s} V_{t}}\right)\right. \\
& \left.-\frac{V_{\mathrm{mpp}}+I_{\mathrm{mpp}} R_{s}}{R_{\mathrm{sh}}}\right) .
\end{aligned}
$$

Unlike in ref. [55] where $R_{s}$ is arbitrarily selected, this iterative process involves determining the $R_{s}$ and $R_{\text {sh }}$ pair using equation (32) by selecting the values of $A$ that are less than $A_{o}$ and subsequently obtaining $P_{\text {mpp }}$ without necessarily plotting the PV curve. Moreover, the ideality factor is adjusted in order to get an $R_{s}$ and $R_{\text {sh }}$ pair that guarantees $P_{\text {mpp }}=V_{\text {mpp }} I_{\text {mpp }}$ that matches $P_{\text {mpp }}$ in the datasheet. This process is repeated until the value of simulated $P_{\text {mpp }}$ matches the maximum power value in the datasheet or has an error margin of less than $0.5 \%$ [22].

The value of $I_{\mathrm{ph}}$ in equation (33) can be calculated using equation (9). The percentage error in power can be determined by calculating the simulated maximum power minus maximum power using $I_{\mathrm{mpp}}$ and $V_{\mathrm{mpp}}$ from datasheet as expressed in the following equation:

$$
P_{\mathrm{mpp}} \text { Error }=\Delta P_{\mathrm{mpp}} \%=\frac{P_{\mathrm{mpp}}-I_{\mathrm{mpp}} V_{\mathrm{mpp}}}{I_{\mathrm{mpp}} V_{\mathrm{mpp}}} \times 100 \% \text {. }
$$

3.4.2. Evaluation of $R_{s h}$ and $R_{s}$ Based on $A$ above $A_{o}$ (Method 2). Similar derivation has been used in equation (31) by replacing $I_{o}$ with $I_{o_{\mathrm{opt}}}$ of equation (14) to obtain

$$
R_{\mathrm{sh}}=\frac{V_{\mathrm{mpp}}-I_{\mathrm{mpp}} R_{s}}{I_{\mathrm{mpp}}-I_{\mathrm{sc}} / A N_{s} V_{t} \exp \left(-V_{\mathrm{oc}} / A_{\mathrm{o}} N_{s} V_{t}\right)\left(V_{\mathrm{mpp}}-I_{\mathrm{mpp}} R_{s}\right) \exp \left(\left(V_{\mathrm{mpp}}+I_{\mathrm{mpp}} R_{s}\right) / A N_{s} V_{t}\right)} .
$$

Equation (35) gives realistic and viable $\left[R_{s}, R_{\mathrm{sh}}\right]$ pairs if and only if the values of ideality factor are above $A_{o}$.

3.4.3. Characterization of $R_{s h}$ and $R_{s}$. The simplest and most convenient way of displaying the relationship between $R_{\mathrm{sh}}$ and $R_{s}$ is through a graphical method using $R_{\text {sh }}$ against $R_{s}$ plots of equation (32) as illustrated in Figure 3 for BP3235T, Kyocera KC200GT, BP-SX 150, and Solarex MSX60 solar modules.

The values of $R_{s}$ have been chosen between 0 and 10 ohms to obtain a positive value of $R_{\text {sh }}$ using simple code in GNU Octave software. For any choice of ideality factor, there are $R_{s}$ and $R_{\text {sh }}$ pairs with nonzero value of $R_{s}$. Further, as illustrated in Figure $3, R_{\mathrm{sh}}$ has positive and negative values for various $R_{s}$.

\section{Parameter Calculation Procedure}

The flowchart shown in Figure 4 gives step by step procedures that have been used to determine all the desired parameters. The immediate action is to obtain the $I_{\mathrm{sc}}, I_{\mathrm{mpp}}, V_{\mathrm{mpp}}$, and $V_{\mathrm{oc}}$ from the datasheet followed by direct calculation of the optimal ideality factor $\left(A_{o}\right)$ using equation (12) and $I_{o}$ using equation (14). $R_{s}$ and $R_{\mathrm{sh}}$ are evaluated using equation (32) for different values of $A_{s}$ in the neighborhood of $A_{o}$ such that $1 \leq A \leq A_{o}$. Consequently, $I_{\mathrm{ph}}$ is calculated using equation (9). The actual saturation current $\left(I_{o}\right)$ corresponding to each ideality factor is recalculated using equation (14).

The maximum power $\left(P_{\mathrm{mpp}}\right)$ is calculated using equation (33) using a simple code in GNU Octave software. Further, $V_{\text {oc }}$ error is calculated by comparing the simulated $V_{\text {oc }}$ of equation (3) values with the datasheet values. These procedures are repeated several times as shown in Figure 4. However, the process is stopped if a maximum power error is less than $0.5 \%$ and/or the short circuit voltage is greater than $0.1 \%$. Calculated values of $I_{o}, R_{\mathrm{sh}}, R_{s}$, and $I_{\mathrm{ph}}$ and simulated values of $V_{\mathrm{oc}}$ and $P_{\mathrm{mpp}}$ and errors for different ideality factors near $A_{o}$ are summarized in Tables 2-5. Eminently, the instantaneous value of $R_{s}$ increases as the ideality factor $\left(A_{s}\right)$ decreases. Thus, the most suitable ideality factor should be chosen near $A_{o}$ provided the errors in $P_{\mathrm{mpp}}$ and $V_{\mathrm{oc}}$ are within the acceptable limits of less than $0.5 \%$ and $0.1 \%$, respectively [22]. The same procedure is repeated when implementing the second approach. The only changes effected are replacement of equation (32) with (35), and ideality factors $\left(A_{s}\right)$ are selected above $A_{o}$.

\section{Analysis of Extracted Parameters and Simulated Data}

Table 2 gives a summary of extracted parameters and simulated data for $P_{\mathrm{mpp}}$ and $V_{\mathrm{oc}}$ and their respective errors for BP3235T PV solar module. As depicted in equations (32) and (33) and verified in Figure 3, the shunt resistance varies greatly within a small range of series resistance. Henceforth, the series resistance has been used as the lead parameter that controls the interactive process that stops when appropriate $R_{s}$ is reached which guarantees simulated data match the experimental data. In this work, the experimental data are obtained from the information available in the manufacturer's datasheet.

For BP3235T PV solar module, the value of ideality factor has been kept constant at $A=1.792$ since it provided satisfactory $\left[R_{s}, R_{\mathrm{sh}}\right]$ pair that resulted to a small error at both maximum power point and $V_{\text {oc }}$. Rs $3=0.242 \Omega$ presented the least $\Delta V_{\mathrm{oc}}$ and $\Delta P_{\mathrm{mpp}}$ errors of $0 \%$ and $0.001 \%$, respectively. The values of $R_{s}$ have been varied and checked within $\pm 1 \mathrm{~m} \Omega$, which are presented in Table 2 as Rs 1 to Rs4, and offer satisfactory results as compared to other data published in $[25,71]$ as discussed later in Section 7.

Tables 3-5 give similar summary for KC200GT, BP-SX 150, and MSX60 PV modules. For KC200GT, BP-SX 150, and MSX60 PV, the values corresponding to Rs $4=0.2188 \Omega$, 


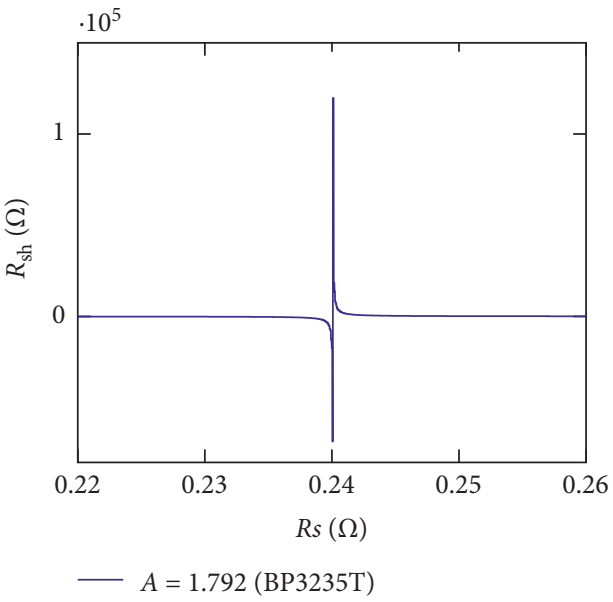

(a)

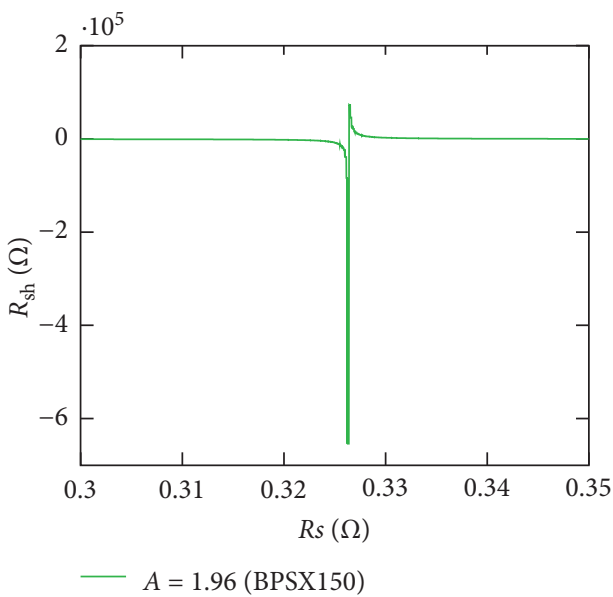

(c)

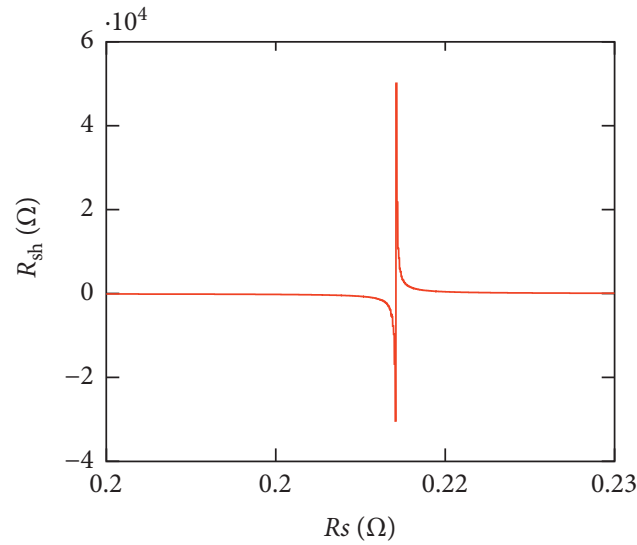

$A=1.809(\mathrm{KC} 200 \mathrm{GT})$

(b)

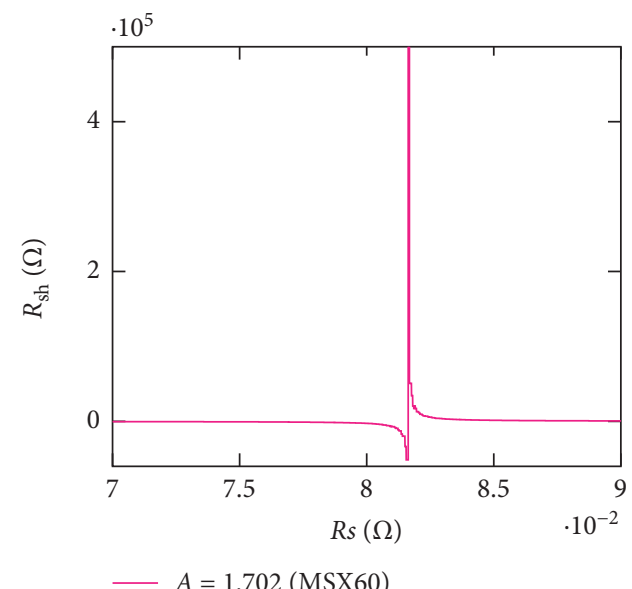

(d)

Figure 3: A graph of $R_{\mathrm{sh}}$ vs $R_{\mathrm{s}}$ at STC for (a) BP3235T, (b) Kyocera KC200GT, (c) BP-SX 150, and (d) Solarex MSX60.

Rs4 $=0.3301 \Omega$, and Rs5 $=0.15 \Omega$, respectively, present the least errors of less than $0.1 \%$ based on the first method. These modules have been chosen to ensure that the tests cover a wide variety of systems with different output power. This shows how valid the proposed approach is for various PV systems.

In the second procedure, where ideality factors $\left(A_{s}\right)$ are selected above $A_{o}$, the same $R_{s}$ values of $R_{\mathrm{s}} 4=0.2188 \Omega$, Rs $4=0.3301 \Omega$, and Rs $5=0.15 \Omega$ have been set as the target for determining the $\left[R_{s}, R_{\mathrm{sh}}\right]$ pair. As illustrated in Tables 3-5, the second approach, unlike the first method, results in unsatisfactory data with $\Delta V_{\text {oc }}$ and $\Delta P_{\text {mpp }}$ errors reaching and exceeding 0.5 percent. This makes the first approach superior over the second one.

Table 6 gives a summary of appropriate parameters for MSX60, BP-SX 150, KC200GT, and BP3235T.

\section{PV Characteristics at Standard Test Conditions}

This proposed technique is a straightforward way of evaluating the desired unknown parameters of a single- diode PV model. The extracted parameters presented in this work can be characterized using IV and/or PV plots. The output power of the solar cell/module can be calculated and evaluated using equation (1) multiplied by the output voltage to obtain

$$
P=V I=V\left(I_{\mathrm{ph}}+I_{o}-I_{o} \exp \left(\frac{V+I R_{s}}{A N_{s} V_{t}}\right)-\frac{V}{R_{\mathrm{sh}}}-\frac{I R_{s}}{R_{\mathrm{sh}}}\right) .
$$

For simplified and clear description of the distinctive variation of PV output power, we have chosen to verify its behavior with respect to identified parameter through PV plots. The PV characteristics are plotted as shown in Figures $5-8$ by using the extracted parameters in equation (36) and using a powerful tool/software with built-in plotting and visualization capability such as MATLAB and Octave.

As shown in Figures 5(a), 6(a), 7(a), and 8(a) for ideality factors below $A_{o}$, the output power plots are closer to the expected result, closer to the datasheet values. This is in conformity with the data presented in Tables 2-5. 


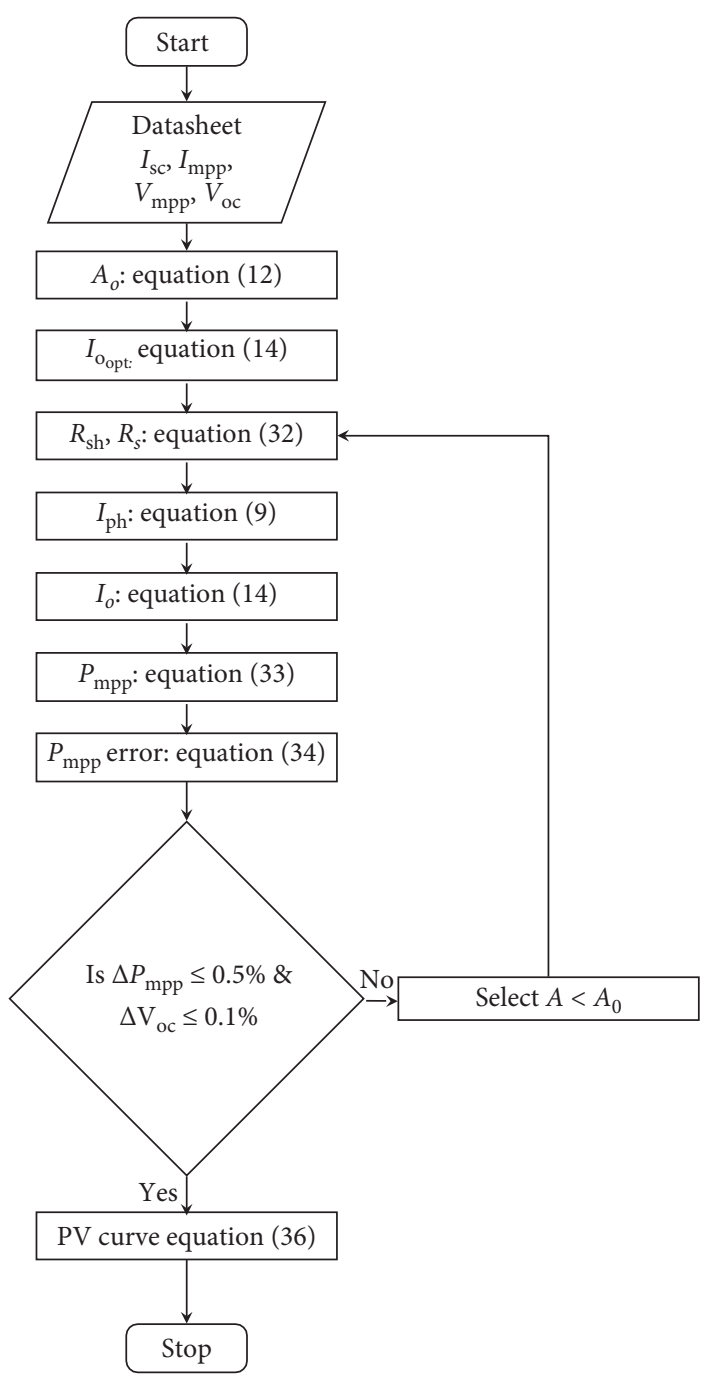

FIGURE 4: An algorithm for evaluating the $A_{o}, A, I_{o_{\text {opt }}}, I_{o}, R_{\mathrm{sh}}$, and $R_{s}$ using manufacturer's datasheet.

TABLE 2: Extracted parameters and data from simulations for BP3235T.

\begin{tabular}{|c|c|c|c|c|c|c|c|c|c|}
\hline & $R_{s}(\Omega)$ & $A<A_{o}$ & $I_{o}(\mathrm{~A})$ & $R_{\mathrm{sh}}(\Omega)$ & $I_{\mathrm{ph}}(\mathrm{A})$ & $V_{\mathrm{oc}}(\mathrm{V})$ & $\Delta V_{\text {oc }}(\%)$ & $P_{\mathrm{mpp}}(\mathrm{W})$ & $\Delta P_{\mathrm{mpp}}(\%)$ \\
\hline \multicolumn{10}{|c|}{ Method 1} \\
\hline Rs1 & 0.002 & $1.801956\left(A_{o}\right)$ & $1.286446 E-5$ & 2195.78 & 8.4800 & 37.194 & -0.016 & 234.17 & -0.405 \\
\hline Rs2 & 0.2419 & 1.792 & $1.194159 E-5$ & 1146.06 & 8.4818 & 37.201 & 0.003 & 235.17 & 0.020 \\
\hline Rs3 & 0.242 & 1.792 & $1.194159 E-5$ & 1066.37 & 8.4819 & 37.2 & 0 & 235.12 & -0.001 \\
\hline Rs4 & 0.2421 & 1.792 & $1.194159 E-5$ & 997.02 & 8.4821 & 37.199 & -0.003 & 235.06 & -0.026 \\
\hline Rs4 & 0.2422 & 1.792 & $1.194159 E-5$ & 936.10 & 8.4822 & 37.198 & -0.005 & 235 & -0.052 \\
\hline \multicolumn{10}{|c|}{ Method 2} \\
\hline Rs1 & 0.0852 & $1.801956\left(A_{o}\right)$ & $1.286446 E-5$ & 6595.76 & 8.4801 & 37.2 & 0 & 235.42 & 0.127 \\
\hline Rs2 & 0.2419 & 1.8626 & $1.989991 E-5$ & 992.72 & 8.4821 & 37.199 & -0.003 & 232.96 & -0.920 \\
\hline Rs3 & 0.242 & 1.8626 & $1.989991 E-5$ & 1066.30 & 8.4819 & 37.199 & -0.003 & 233.03 & -0.890 \\
\hline Rs4 & 0.2421 & 1.8626 & $1.989991 E-5$ & 1151.68 & 8.4818 & 37.2 & 0 & 233.09 & -0.864 \\
\hline Rs5 & 0.2422 & 1.8626 & $1.989991 E-5$ & 1251.95 & 8.4817 & 37.201 & 0.003 & 233.14 & -0.843 \\
\hline
\end{tabular}

The zoomed parts represent the maximum power points and the open circuit voltages, respectively. The curves demonstrate validity of simulated values where the critical points of open circuit voltage and maximum power point have very minimal and acceptable deviation of less than $0.1 \%$.
The plots for Figures 5(b), 6(b), 7(b), and 8(b) whose ideality factors have been selected above $A_{o}$ clearly show a significant deviation at maximum power point. This is also shown in Tables $2-5$ where the errors in maximum power and short circuit voltage surpass 0.5 percent. The data also show errors above 0.5 percent for high-output power modules like 
TABLE 3: Extracted parameters and data from simulations for Kyocera KC200GT.

\begin{tabular}{|c|c|c|c|c|c|c|c|c|c|}
\hline & $R_{s}(\Omega)$ & $A<A_{o}$ & $I_{o}(A)$ & $R_{\mathrm{sh}}(\Omega)$ & $I_{\mathrm{ph}}(\mathrm{A})$ & $V_{\mathrm{oc}}(\mathrm{V})$ & $\Delta V_{\mathrm{oc}}(\%)$ & $P_{\mathrm{mpp}}(\mathrm{W})$ & $\Delta P_{\mathrm{mpp}}(\%)$ \\
\hline \multicolumn{10}{|c|}{ Method 1} \\
\hline Rs1 & 0.001 & $1.81928\left(A_{o}\right)$ & $1.7807 E-5$ & 3636.875 & 8.2100 & 32.897 & -0.0091 & 200.24 & 0.048 \\
\hline Rs2 & 0.2186 & 1.809 & $1.65353 E-5$ & 1219.678 & 8.2115 & 32.902 & 0.0061 & 200.22 & 0.038 \\
\hline Rs3 & 0.2187 & 1.809 & $1.65353 E-5$ & 1116.104 & 8.2116 & 32.901 & 0.0030 & 200.17 & 0.013 \\
\hline Rs4 & 0.2188 & 1.809 & $1.65353 E-5$ & 1028.696 & 8.2118 & 32.9 & 0 & 200.12 & -0.011 \\
\hline Rs5 & 0.2189 & 1.809 & $1.65353 E-5$ & 953.941 & 8.2119 & 32.9 & 0 & 200.07 & -0.036 \\
\hline \multicolumn{10}{|c|}{ Method 2} \\
\hline Rs1 & 0.0718 & $1.81928\left(A_{o}\right)$ & $1.78074 E-5$ & 7020.18 & 8.2101 & 32.9 & 0 & 200.66 & 0.26 \\
\hline Rs2 & 0.2186 & 1.882 & $2.75010 E-5$ & 612.69 & 8.2130 & 32.893 & -0.021 & 197.84 & -1.15 \\
\hline Rs3 & 0.2187 & 1.882 & $2.75010 E-5$ & 644.29 & 8.2128 & 32.894 & -0.018 & 197.89 & -1.13 \\
\hline Rs4 & 0.2188 & 1.882 & $2.75010 E-5$ & 679.35 & 8.2127 & 32.894 & -0.018 & 197.97 & -1.09 \\
\hline Rs5 & 0.2189 & 1.882 & $2.75010 E-5$ & 718.45 & 8.2125 & 32.895 & -0.015 & 198.06 & -1.04 \\
\hline
\end{tabular}

TABLE 4: Extracted parameters and data from simulations for BP-SX 150.

\begin{tabular}{|c|c|c|c|c|c|c|c|c|c|}
\hline & $R_{s}(\Omega)$ & $A<A_{o}$ & $I_{o}(\mathrm{~A})$ & $R_{\mathrm{sh}}(\Omega)$ & $I_{\mathrm{ph}}(\mathrm{A})$ & $V_{\mathrm{oc}}(\mathrm{V})$ & $\Delta V_{\mathrm{oc}}(\%)$ & $P_{\mathrm{mpp}}(\mathrm{W})$ & $\Delta P_{\mathrm{mpp}}(\%)$ \\
\hline \multicolumn{10}{|c|}{ Method 1} \\
\hline Rs1 & 0.004 & $1.96721\left(A_{o}\right)$ & $3.03832 E-5$ & 94045.01 & 4.7500 & 43.5 & 0 & 150.18 & 0.070 \\
\hline Rs2 & 0.3295 & 1.96 & $2.90755 E-5$ & 5001.02 & 4.7503 & 43.509 & 0.0207 & 150.16 & 0.057 \\
\hline Rs3 & 0.3297 & 1.96 & $2.90755 E-5$ & 4555.72 & 4.7504 & 43.508 & 0.0184 & 150.14 & 0.043 \\
\hline Rs4 & 0.3299 & 1.96 & $2.90755 E-5$ & 4183.07 & 4.7504 & 43.507 & 0.0161 & 150.12 & 0.030 \\
\hline Rs5 & 0.3301 & 1.96 & $2.90755 E-5$ & 3866.64 & 4.7504 & 43.507 & 0.0161 & 150.09 & 0.010 \\
\hline \multicolumn{10}{|c|}{ Method 2} \\
\hline Rs1 & 0.1272 & $1.96721\left(A_{o}\right)$ & $3.03832 E-5$ & 10277.75 & 4.7501 & 43.499 & -0.0023 & 150.09 & 0.0100 \\
\hline Rs2 & 0.3295 & 2.007 & $3.85129 E-5$ & 7860.56 & 4.7502 & 43.510 & 0.0230 & 149.38 & -0.4631 \\
\hline Rs3 & 0.3297 & 2.007 & $3.85129 E-5$ & 10013.81 & 4.7502 & 43.511 & 0.025 & 149.42 & -0.4364 \\
\hline Rs4 & 0.3299 & 2.007 & $3.85129 E-5$ & 13793.17 & 4.7501 & 43.512 & 0.028 & 149.43 & -0.4298 \\
\hline Rs5 & 0.3301 & 2.007 & $3.85129 E-5$ & 22158.12 & 4.7501 & 43.513 & 0.03 & 149.47 & -0.4031 \\
\hline
\end{tabular}

TABLe 5: Extracted parameters and data from simulations for Solarex MSX60.

\begin{tabular}{|c|c|c|c|c|c|c|c|c|c|}
\hline & $R_{s}(\Omega)$ & $A<A_{o}$ & $I_{o}(\mathrm{~A})$ & $R_{\mathrm{sh}}(\Omega)$ & $I_{\mathrm{ph}}(\mathrm{A})$ & $V_{\mathrm{oc}}(\mathrm{V})$ & $\Delta V_{\mathrm{oc}}(\%)$ & $P_{\mathrm{mpp}}(\mathrm{W})$ & $\Delta P_{\mathrm{mpp}}(\%)$ \\
\hline \multicolumn{10}{|c|}{ Method 1} \\
\hline Rs1 & 0.001 & $1.70418\left(A_{o}\right)$ & $5.79749 E-06$ & 5989.76 & 3.8000 & 21.1 & 0 & 59.86 & 0.0184 \\
\hline Rs2 & 0.147 & 1.7 & $5.60956 E-06$ & 21759.59 & 3.8000 & 21.106 & 0.0284 & 59.91 & 0.0986 \\
\hline Rs3 & 0.148 & 1.7 & $5.60956 E-06$ & 3127.83 & 3.8002 & 21.104 & 0.0190 & 59.83 & -0.0284 \\
\hline Rs4 & 0.149 & 1.7 & $5.60956 E-06$ & 1681.73 & 3.8003 & 21.102 & 0.0095 & 59.76 & -0.1487 \\
\hline Rs5 & 0.150 & 1.7 & $5.60956 E-06$ & 1148.49 & 3.8005 & 21.100 & 0.0000 & 59.68 & -0.2840 \\
\hline \multicolumn{10}{|c|}{ Method 2} \\
\hline Rs1 & 0.0351 & $1.70418\left(A_{o}\right)$ & $5.79749 E-06$ & 3409.80 & 3.8000 & 21.1 & 0 & 59.87 & 0.0251 \\
\hline Rs2 & 0.147 & 1.737 & $7.46677 E-06$ & 733.8600 & 3.8008 & 21.095 & -0.0237 & 59.22 & -1.0560 \\
\hline Rs3 & 0.148 & 1.737 & $7.46677 E-06$ & 1052.9594 & 3.8005 & 21.098 & -0.0095 & 59.39 & -0.7686 \\
\hline Rs4 & 0.149 & 1.737 & $7.46677 E-06$ & 1866.4501 & 3.8003 & 21.102 & 0.0095 & 59.47 & -0.6383 \\
\hline Rs5 & 0.150 & 1.737 & $7.46677 E-06$ & 8273.5534 & 3.8001 & 21.106 & 0.0284 & 59.58 & -0.4478 \\
\hline
\end{tabular}

TABLE 6: A summary of appropriate parameters for MSX60, BP-SX 150, KC200GT, and BP3235T.

\begin{tabular}{|c|c|c|c|c|c|c|c|c|}
\hline & \multicolumn{2}{|c|}{ MSX60 } & \multicolumn{2}{|c|}{ BP-SX 150} & \multicolumn{2}{|c|}{ KC200GT } & \multicolumn{2}{|c|}{ BP3235T } \\
\hline & Method 1 & Method 2 & Method 1 & Method 2 & Method 1 & Method 2 & Method 1 & Method 2 \\
\hline$R_{s}(\Omega)$ & 0.150 & 0.150 & 0.3301 & 0.3301 & 0.2188 & 0.2188 & 0.2420 & 0.2420 \\
\hline$R_{\mathrm{sh}}(\Omega)$ & 1148.49 & 8273.5533 & 3866.64 & 22158.12 & 1028.695 & 679.35 & 1066.37 & 1066.30 \\
\hline$A$ & 1.7 & 1.737 & 1.96 & 2.007 & 1.809 & 1.882 & 1.7920 & 1.8626 \\
\hline$I_{o}(\mathrm{~A})$ & $5.6096 E-6$ & $7.4668 E-06$ & $2.9076 E-5$ & $3.8513 E-5$ & $1.6535 E-5$ & $2.7501 E-5$ & $1.1942 E-5$ & $1.99 E-5$ \\
\hline$I_{\mathrm{ph}}(\mathrm{A})$ & 3.800013 & 3.8001 & 4.7504 & 4.7501 & 8.2119 & 8.2127 & 8.481938 & 8.4819 \\
\hline
\end{tabular}




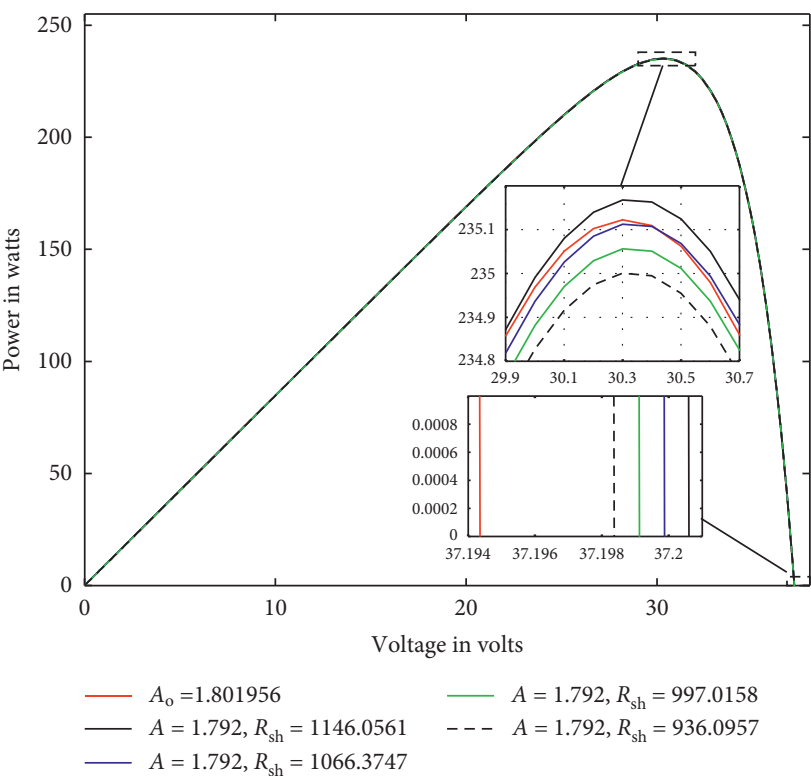

(a)

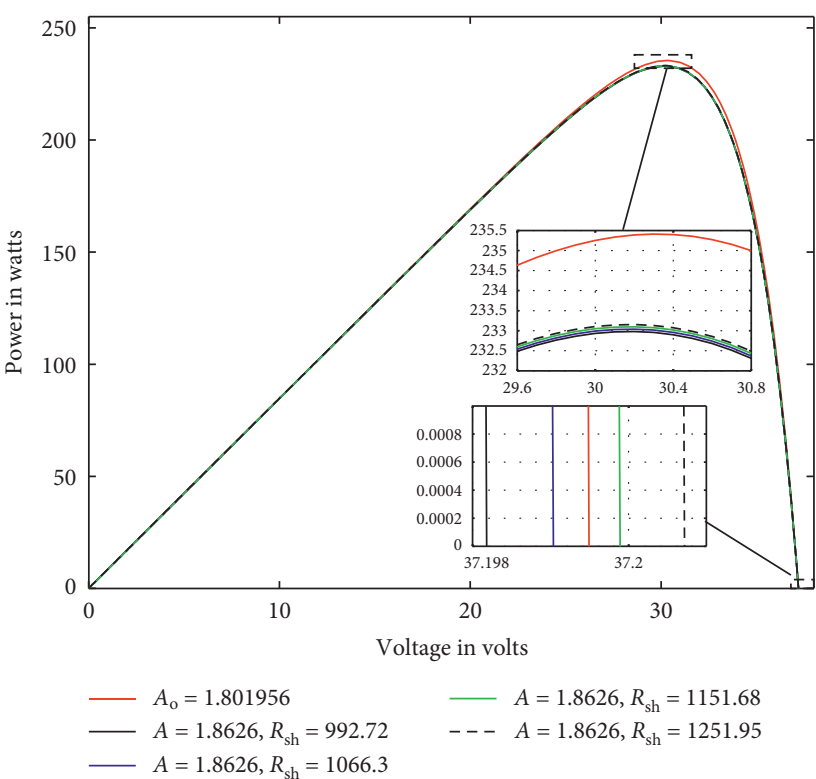

(b)

Figure 5: PV curves for BP3235T showing different ( $\left.R_{\mathrm{sh}}\right)$ values for (a) $A<A_{o}$ and (b) $A>A_{o}$.

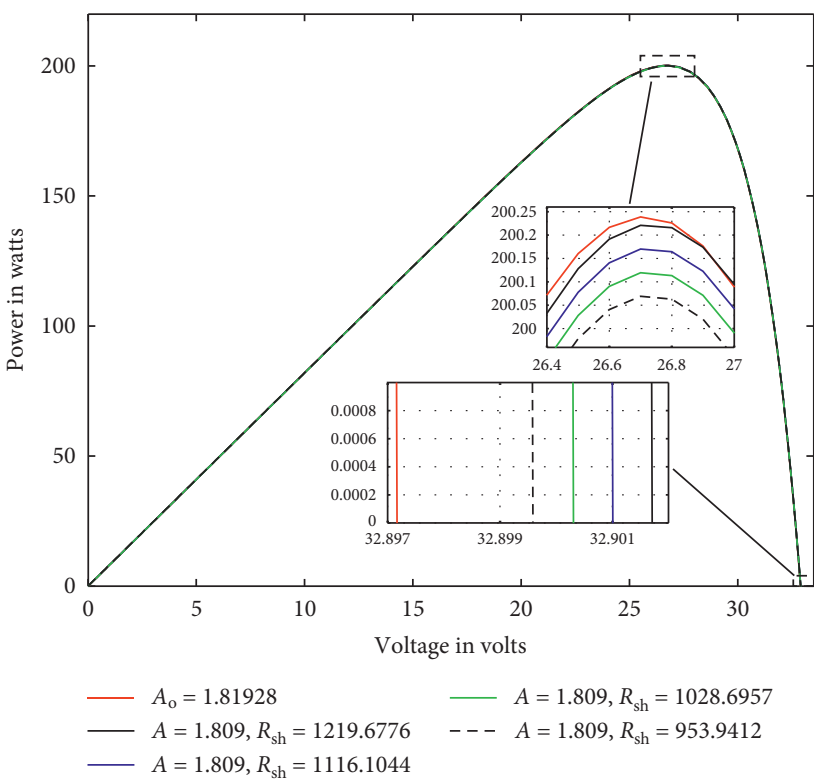

(a)

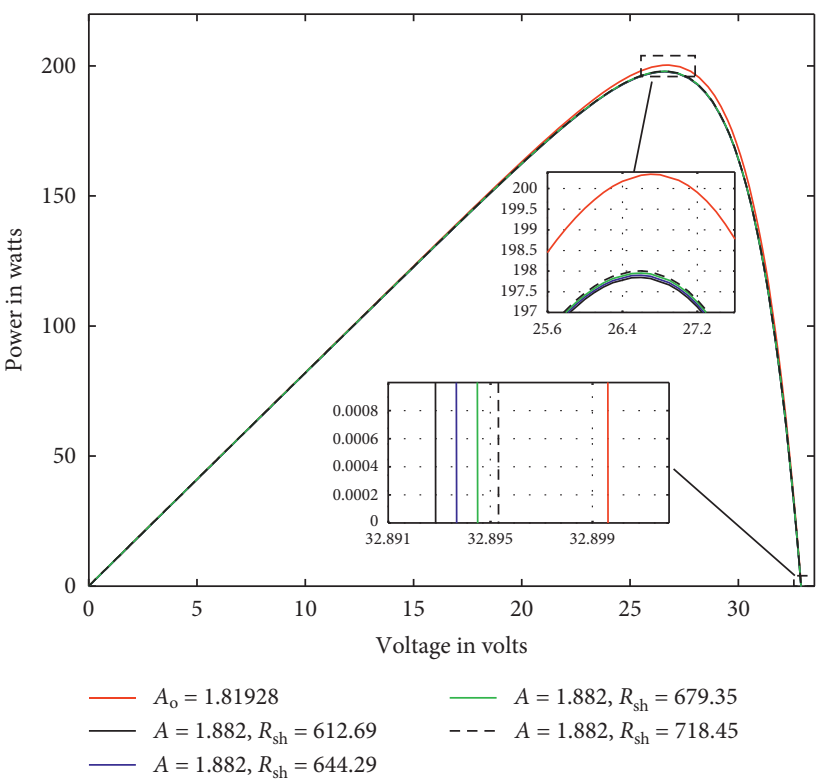

(b)

Figure 6: PV curves for KC200GT showing different $\left(R_{\mathrm{sh}}\right)$ values for (a) $A<A_{o}$ and (b) $A>A_{o}$.

Kyocera 200GT and BP2235T. In order to overcome this drawback, the ideality factor can be selected very close to $A_{o}$ and consequently other parameters can be changed which will result in small errors. However, this reduces the values of $R_{s}$, and care must be taken not to get nonviable values.

\section{Comparison of the Proposed Analytical Method with Other Related Works}

In this paper, the ideality factor, the saturation current, and the series resistance are the three key parameters that have been carefully evaluated and considered to have a major impact on the PV relationship compared to the shunt resistance and $I_{\mathrm{ph}}$. Since the ideality factor has been considered as the immediate parameter to be calculated, the next critically analyzed parameter is the saturation current using equations (13) to (18). Furthermore, due to the nonlinearity of the equations that relate to these parameters, it has been important to use iterative solutions for series and shunt resistances.

As shown in Tables 7-9, ideality factors between 1 and 1.5 have lower $I_{o}$ values than ideal factors closer to $A_{o}$. 


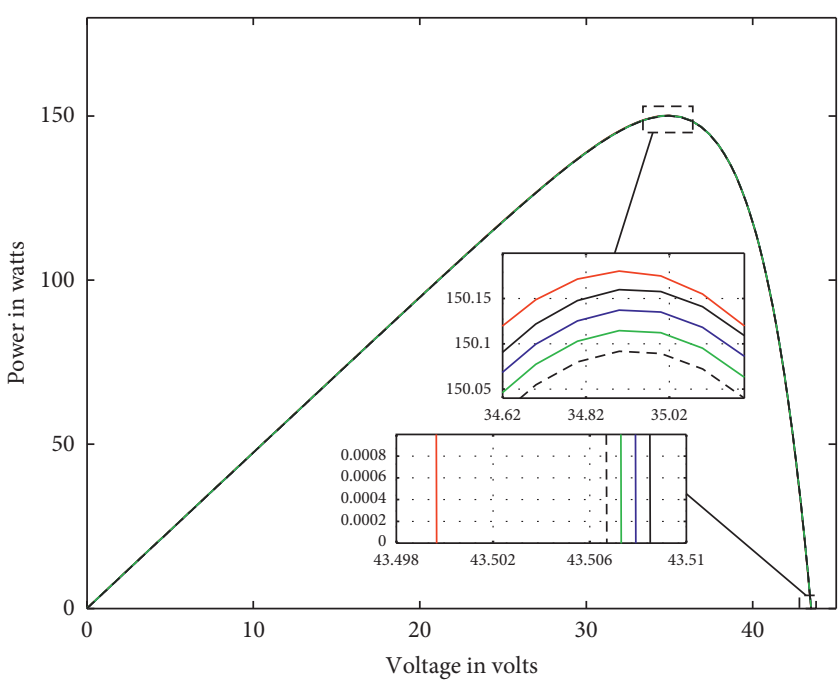

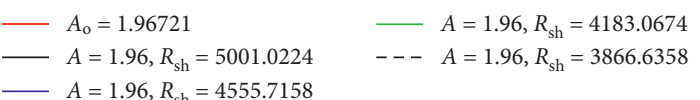

(a)

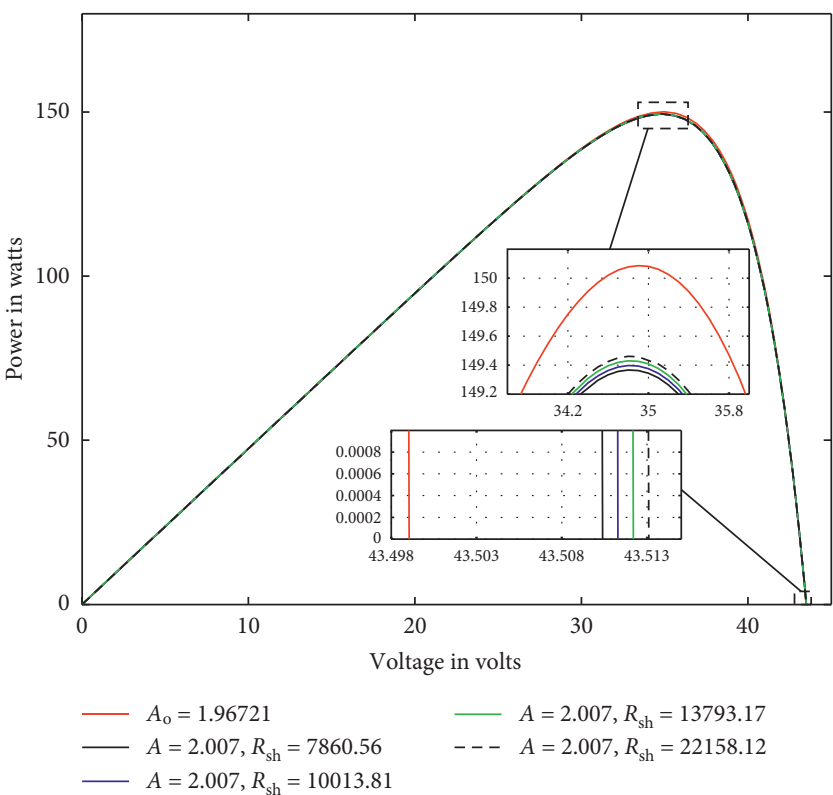

(b)

Figure 7: PV curves for BP-SX 150 showing different ( $\left.R_{\mathrm{sh}}\right)$ values for (a) $A<A_{o}$ and (b) $A>A_{o}$.

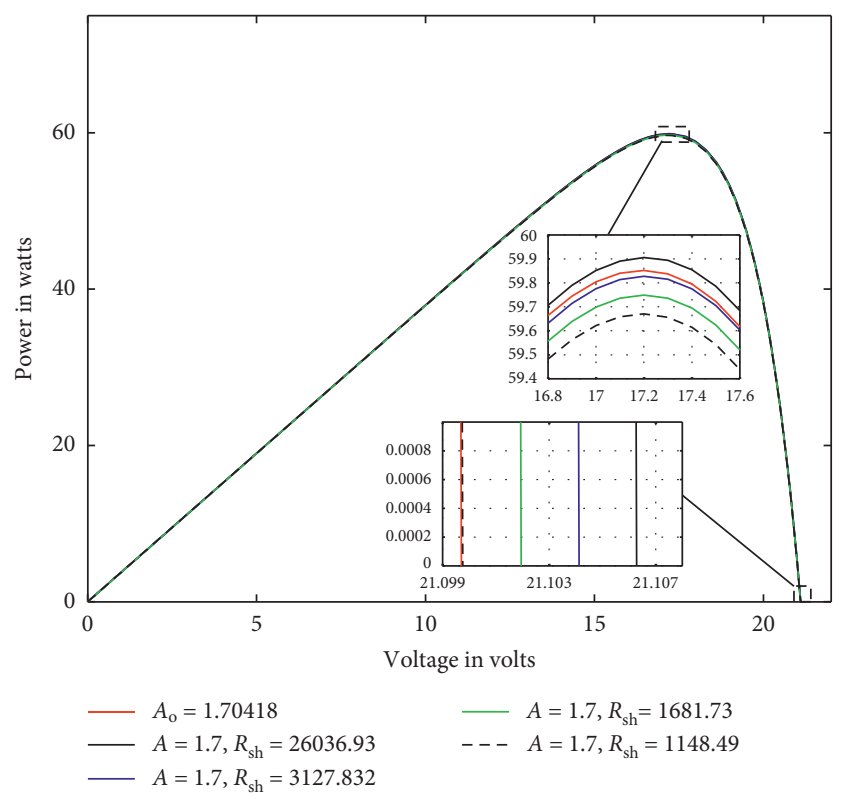

(a)

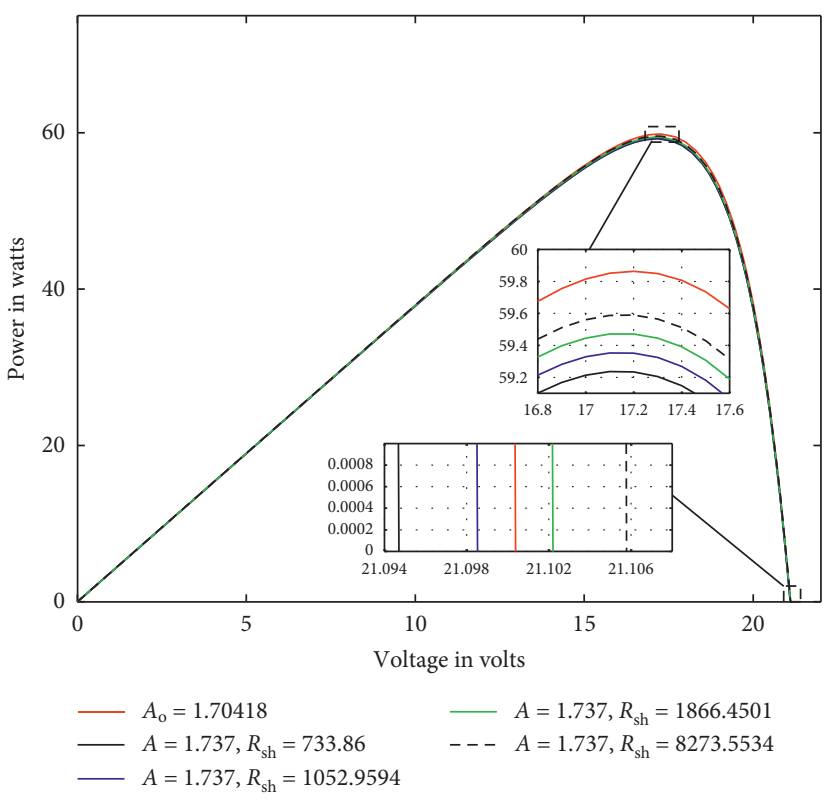

(b)

Figure 8: PV curves for MSX60 showing different $\left(R_{\mathrm{sh}}\right)$ values for (a) $A<A_{o}$ and (b) $A>A_{o}$.

Depending on which parameters are calculated first, different approaches result to different values of $I_{0}$. For instance, if $A, R_{s}$, and $R_{\mathrm{sh}}$ are calculated first, then equations (13) and (15) can be used to calculate $I_{o}$; otherwise, simplified approaches found in $[6,19]$ that first assume $R_{s} \approx 0$ and $R_{\mathrm{sh}} \approx \infty$ to obtain $I_{o}$ have been applied here using equations (14), (16), and (18). Equation (17) gives negative values of $I_{o}$ and has not been considered here. This accounts for the diverse findings published in previous works such as works of $[25,71]$ for BP32235T, findings in $[52,55,58,61,66]$ for Kyocera 200GT, reports in [61, 72, 73] for BP-SX 150, and studies in $[25,61,70,72]$ for MSX60. The studies in $[52,55,57-59,61,71]$ used equation (13) to calculate $I_{o}$, which provided reliable results that are consistent with the results obtained in this study.

For BP32235T given in Table 7, consistent findings in the works of $[25,71]$ recorded appropriate values for $R_{s}, R_{\mathrm{sh}}$, and $I_{\mathrm{ph}}$ within the same range as the values obtained in this work. 
TABLE 7: Calculated parameters and data from simulations for BP3235T.

\begin{tabular}{|c|c|c|c|c|}
\hline Parameters & Method 1 & Method 2 & Ref. [25] & Ref. [71] \\
\hline$R_{s}(\Omega)$ & 0.2420 & 0.2420 & 0.336 & 0.2371 \\
\hline$R_{\mathrm{sh}}(\Omega)$ & 1066.3747 & 1066.30 & 652.09 & 4393.8 \\
\hline$A$ & 1.7920 & 1.8626 & 1.01 & 1.34 \\
\hline$I_{o}(\mathrm{~A})$ & $1.194159 E-05$ & $1.989991 E-5$ & $4.610 E-10$ & $1.29 E-07$ \\
\hline$I_{\mathrm{ph}}(\mathrm{A})$ & 8.481938 & 8.4819 & 8.4929 & 8.4805 \\
\hline$I_{o}(\mathrm{~A})$, equation $(3)[55]$ & $1.19416 E-05$ & $1.99000 E-05$ & $3.52066 E-10$ & $1.26861 E-07$ \\
\hline$I_{o}$, equation $(3)$ & $1.18925 E-05$ & $1.98181 E-05$ & $3.49697 E-10$ & $1.26735 E-07$ \\
\hline$I_{o}$, equation (13) [61] & $1.18952 E-05$ & $1.98227 E-05$ & $3.49879 E-10$ & $1.26741 E-07$ \\
\hline$I_{o}$, equation $(14)$ & $1.19416 E-05$ & $1.98999 E-05$ & $3.52066 E-10$ & $1.26861 E-07$ \\
\hline$I_{o}$, equation $(15)$ & $5.78361 E-06$ & $8.93832 E-06$ & $4.78243 E-10$ & $1.27022 E-07$ \\
\hline$I_{o}$, equation (16) & $1.21197 E-05$ & $1.82458 E-05$ & $2.84624 E-09$ & $3.17969 E-07$ \\
\hline$I_{o}$, equation (18) & $1.19285 E-05$ & $2.00357 E-05$ & $3.30414 E-10$ & $3.17969 E-07$ \\
\hline
\end{tabular}

TABLE 8: Calculated parameters and data from simulations for KC200GT.

\begin{tabular}{|c|c|c|c|c|c|c|c|c|}
\hline Parameters & Method 1 & Method 2 & Ref. [52] & Ref. [55] & Ref. [58] & Ref. [61] & Ref. [66] & Ref. [59] \\
\hline$R_{s}(\Omega)$ & 0.2188 & 0.2188 & 0.217 & 0.221 & 0.231 & 0.217 & 0.2108 & 0.21095 \\
\hline$R_{\mathrm{sh}}(\Omega)$ & 953.941 & 679.35 & 951.927 & 415.405 & 594.851 & 951.92 & 145.083 & 192.757 \\
\hline$A$ & 1.809 & 1.882 & 1.34 & 1.3 & 1.3 & 1.342 & 1.1578 & 1.1482 \\
\hline$I_{o}(\mathrm{~A})$ & $1.6535 E-5$ & $2.7501 E-5$ & $1.7100 E-7$ & $9.825 E-8$ & $9.6990 E-8$ & $1.71 E-7$ & $1.01 E-8$ & $8.6369 E-9$ \\
\hline$I_{\mathrm{ph}}(\mathrm{A})$ & 8.2119 & 8.2127 & 8.212 & 8.214 & 8.213 & 8.211 & 8.226 & 8.218985 \\
\hline$I_{o}[55]$ & $1.6535 E-5$ & $2.7501 E-5$ & $1.6782 E-7$ & $9.7328 E-8$ & $9.7328 E-8$ & $1.7230 E-7$ & $1.0340 E-8$ & $3.665 E-9$ \\
\hline$I_{o}$, equation $(3)$ & $1.6466 E-5$ & $2.7339 E-5$ & $1.6711 E-7$ & $9.6389 E-8$ & $9.6672 E-8$ & $1.7158 E-7$ & $1.0054 E-8$ & $3.568 E-9$ \\
\hline$I_{o}$, equation (13) & $1.6470 E-5$ & $2.7348 E-5$ & $1.6715 E-7$ & $9.6440 E-8$ & $9.6710 E-8$ & $1.7162 E-7$ & $1.0069 E-8$ & $3.578 E-9$ \\
\hline$I_{o}$, equation (14) & $1.6535 E-5$ & $2.7501 E-5$ & $1.6782 E-7$ & $9.7327 E-8$ & $9.7327 E-8$ & $1.7230 E-7$ & $1.0340 E-8$ & $3.665 E-9$ \\
\hline$I_{o}$, equation (15) & $8.2468 E-6$ & $1.2462 E-5$ & $1.6784 E-7$ & $9.7440 E-8$ & $9.6720 E-8$ & $1.7164 E-7$ & $1.1867 E-8$ & $1.835 E-9$ \\
\hline$I_{o}$, equation (16) & $1.6783 E-5$ & $2.5205 E-5$ & $4.2778 E-7$ & $2.7675 E-7$ & $2.7675 E-7$ & $4.3690 E-7$ & $4.6099 E-8$ & $2.012 E-8$ \\
\hline$I_{o}$, equation (18) & $1.6516 E-5$ & $2.7700 E-5$ & $1.6014 E-7$ & $9.2594 E-8$ & $9.2594 E-8$ & $1.6445 E-7$ & $9.7438 E-9$ & $3.443 E-9$ \\
\hline
\end{tabular}

TABle 9: Calculated parameters and data from simulations for BP-SX 150.

\begin{tabular}{lccccc}
\hline Parameters & Method 1 & Method 2 & Ref. [61] & Ref $([72])$ & Ref $([73])$ \\
\hline$R_{s}(\Omega)$ & 0.3301 & 0.3301 & 0.4543 & 0.312557 & 0.331466 \\
$R_{\mathrm{sh}}(\Omega)$ & 3866.64 & 22158.12 & 960.06 & 1799.371625 & 1.64 \\
$A$ & 1.96 & 2.007 & 1.4851 & 2.679648 \\
$I_{o}(\mathrm{~A})$ & $2.90755 E-05$ & $3.851289 E-05$ & $6.166 E-07$ & $2.8016100 E-06$ & $2.8419820 E-06$ \\
$I_{\text {ph }}(\mathrm{A})$ & 4.7504 & 4.7501 & 4.7522 & 4.750827 & 4.75 \\
$I_{o}$, equation (3) [55] & $2.907545 E-05$ & $3.851320 E-05$ & $6.258569 E-07$ & $2.794604 E-06$ & $2.843865 E-06$ \\
$I_{o}$, equation (3) & $2.900659 E-05$ & $3.849728 E-05$ & $6.198869 E-07$ & $2.780381 E-06$ & $2.837902 E-06$ \\
$I_{o}$, equation (13) [61] & $2.900917 E-05$ & $3.849802 E-05$ & $6.201831 E-07$ & $2.780867 E-06$ & $2.838119 E-06$ \\
$I_{o}$, equation (14) & $2.907528 E-05$ & $3.851289 E-05$ & $6.258568 E-07$ & $2.794602 E-06$ & $2.843864 E-06$ \\
$I_{o}$, equation (15) & $1.930475 E-05$ & $2.480836 E-05$ & $6.196016 E-07$ & $2.784494 E-06$ & $2.830482 E-06$ \\
$I_{o}$, equation (16) & $2.934115 E-05$ & $3.666915 E-05$ & $1.397445 E-06$ & $4.578563 E-06$ & $4.642457 E-06$ \\
$I_{o}$, equation (18) & $2.905107 E-05$ & $3.869178 E-05$ & $5.956163 E-07$ & $2.697940 E-06$ & $2.746036 E-06$ \\
\hline
\end{tabular}

TABle 10: Calculated parameters and data from simulations for Solarex MSX60.

\begin{tabular}{|c|c|c|c|c|c|c|}
\hline Parameters & Method 1 & Method 2 & Ref. [25] & Ref. [61] & Ref. [70] & Ref. [72] \\
\hline$R_{s}(\Omega)$ & 0.150 & 0.150 & 0.234 & 0.169 & 0.2165 & 0.223427 \\
\hline$R_{\mathrm{sh}}(\Omega)$ & 1148.49 & 8273.5534 & 9.29 & 637.5 & 274.937 & 406.346152 \\
\hline$A$ & 1.7 & 1.737 & 1.27 & 1.404 & 1.277 & 1.387 \\
\hline$I_{o}(\mathrm{~A})$ & $5.60956 E-6$ & $7.46677 E-6$ & $5.95 E-8$ & $3.29 E-07$ & $6.4500 E-8$ & $2.97156 E-6$ \\
\hline$I_{\mathrm{ph}}(\mathrm{A})$ & 3.800013 & 3.8001 & 3.8 & 3.801 & 3.813 & 3.872128 \\
\hline$I_{o}$, equation (3) [55] & $5.60957 E-06$ & $7.46678 E-06$ & $5.95254 E-08$ & $3.30851 E-07$ & $6.56881 E-08$ & $2.71080 E-07$ \\
\hline$I_{o}$, equation $(3)$ & $5.58245 E-06$ & $7.46177 E-06$ & $2.39471 E-08$ & $3.27969 E-07$ & $6.43615 E-08$ & $2.67376 E-07$ \\
\hline$I_{o}$, equation (13) $[61]$ & $5.58319 E-06$ & $7.46191 E-06$ & $2.54464 E-08$ & $3.28057 E-07$ & $6.44132 E-08$ & $2.67525 E-07$ \\
\hline$I_{o}$, equation $(14)$ & $5.60956 E-06$ & $7.46677 E-06$ & $5.95254 E-08$ & $3.30851 E-07$ & $6.56881 E-08$ & $2.71080 E-07$ \\
\hline$I_{o}$, equation $(15)$ & $3.84169 E-06$ & $5.09713 E-06$ & $-3.60728 E-07$ & $3.28789 E-07$ & $6.41383 E-08$ & $2.26480 E-07$ \\
\hline$I_{o}$, equation (16) & $5.64471 E-06$ & $7.11705 E-06$ & $1.41800 E-07$ & $5.69360 E-07$ & $1.53585 E-07$ & $4.84460 E-07$ \\
\hline$I_{o}$, equation (18) & $5.60657 E-06$ & $7.49835 E-06$ & $5.67053 E-08$ & $3.19383 E-07$ & $6.26165 E-08$ & $2.61219 E-07$ \\
\hline
\end{tabular}


TABLE 11: Calculated parameters and data from simulations for KC200GT.

\begin{tabular}{|c|c|c|c|c|c|c|}
\hline \multicolumn{7}{|c|}{ Datasheet values } \\
\hline$I_{\mathrm{sc}}(\mathrm{A})$ & $I_{\mathrm{mpp}}(\mathrm{A})$ & $V_{\mathrm{oc}}(\mathrm{V})$ & $V_{\mathrm{mpp}}(\mathrm{V})$ & $K_{I}\left(\mathrm{~A} /{ }^{\circ} \mathrm{C}\right)$ & $K_{V}\left(\mathrm{~V} /{ }^{\circ} \mathrm{C}\right)$ & NOCT $\left({ }^{\circ} \mathrm{C}\right)$ \\
\hline 6.62 & 6.13 & 29.9 & 23.2 & 0.00328 & $(-0.123)$ & 47 \\
\hline \multicolumn{7}{|c|}{ Simulated parameter values } \\
\hline Parameters & $R_{s}(\Omega)$ & $R_{\mathrm{sh}}(\Omega)$ & $\mathrm{A}$ & $I_{o}(\mathrm{~A})$ & $I_{\mathrm{ph}}(\mathrm{A})$ & $T(\mathrm{~K})$ \\
\hline$T=25^{\circ} \mathrm{C}$ & 0.2188 & 1028.685 & 1.809 & $1.6535 E-05$ & 6.5695 & 298.15 \\
\hline$T=47^{\circ} \mathrm{C}$ & 0.233 & 679.35 & 1.808 & $1.0752 E-04$ & 6.6257 & 320.15 \\
\hline Ref. [59] & 0.23901 & 218.40213 & 1.11933 & $4.94422 E-09$ & 6.57518 & 298.15 \\
\hline
\end{tabular}

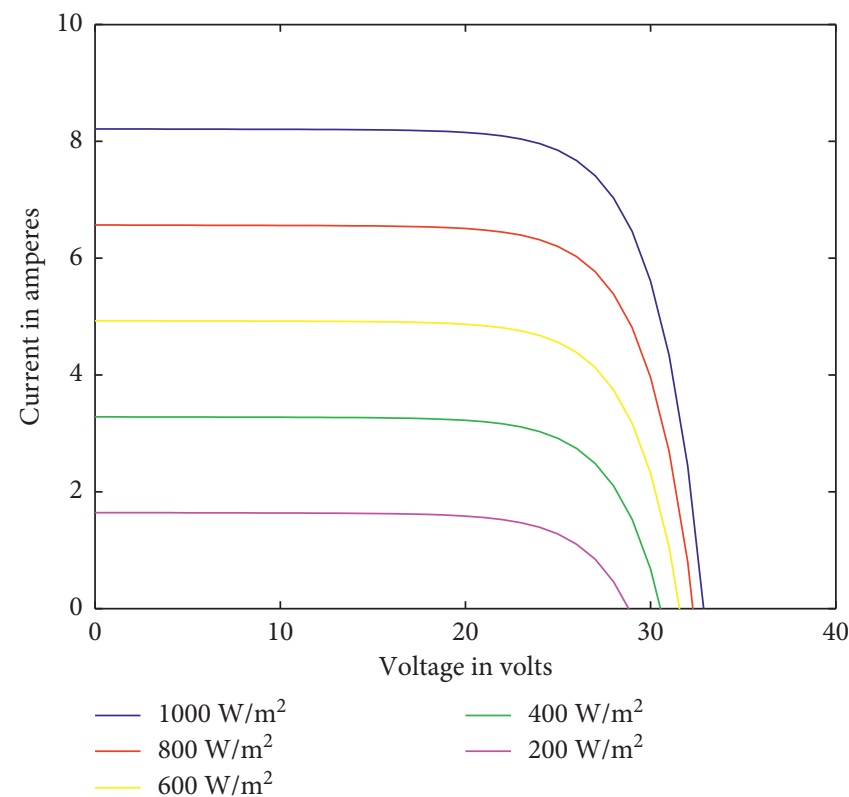

(a)

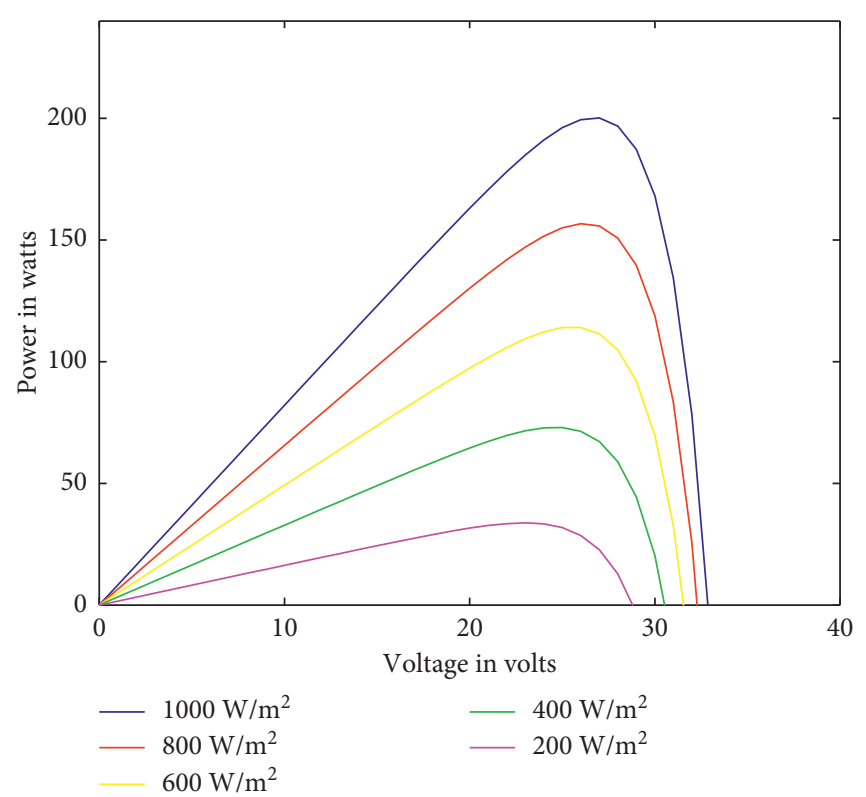

(b)

Figure 9: IV and PV curves for KC200GT showing different irradiance values at $1000 \mathrm{~W} / \mathrm{m}^{2}, 800 \mathrm{~W} / \mathrm{m}^{2}, 600 \mathrm{~W} / \mathrm{m}^{2}, 400 \mathrm{~W} / \mathrm{m}^{2}$, and $200 \mathrm{~W} / \mathrm{m}^{2}$, for $T=25^{\circ} \mathrm{C}$. (a) KC200GT IV curve for $T=25^{\circ} \mathrm{C}$. (b) KC200GT PV curve for $T=25^{\circ} \mathrm{C}$.

Nevertheless, no consistency exists between $A$ and $I_{o}$ values, where higher values of ideality factors $\left(A_{s}\right)$ give large $I_{o}$ values and lower values of ideality factors $\left(A_{s}\right)$ give smaller values of $I_{o}$.

Consistent results have also been reported for Kyocera KC200GT as shown in Table 8 where the works of $[55,58]$ gave closer results for $R_{s}=0.221(\Omega)$ and $R_{s}=0.231(\Omega)$, while the findings reported in $[52,61,66]$ gave $R_{s}=0.217(\Omega)$, $R_{s}=0.217(\Omega)$, and $R_{s}=0.2108(\Omega)$, respectively, which agrees with $R_{s}=0.2188(\Omega)$ reported here. The $R_{\text {sh }}$ values differ with a higher margin, since a minor adjustment in $R_{s}$ in $\mathrm{m} \Omega \mathrm{s}$ is significant enough to shift $R_{\mathrm{sh}}$ exponentially according to equations (32) and (35). The results of $[55,58]$ are higher than those of methods 1 and 2 and those published in $[52,61,66]$ due to the fact that the solutions were obtained for a fixed value of the ideality factor $A=1.3$. In addition, the different choice of ideality factor gives diverse values of $I_{o}$.

For BP-SX 150 data results shown in Table 9, similar and almost matching results were obtained in [73] of $R_{s}=0.331466(\Omega)$ compared with the proposed method in this article of $R_{s}=0.3301(\Omega)$. The works of $[61,72]$ reported higher and lower values of $R_{s}=0.4543(\Omega)$ and
$R_{s}=0.312557(\Omega)$, respectively. Other parameters do not have satisfactory agreements with the parameters extracted here.

For MSX60 data given in Table 10, it is possible to compare the result of $R_{s}=0.15(\Omega)$ using methods 1 and 2 with the results given in [61] of $R_{s}=0.169(\Omega)$ which shows a slight difference. Nevertheless, the results in $[25,70,72]$ have much larger $R_{s}$ values depending on the techniques applied to achieve them, while diverse results are given for other parameters.

\section{Evaluation of the Proposed Method at Different Irradiance Levels and Nominal Operating Cell Temperature}

The proposed technique has also been tested for various irradiance levels and nominal cell operation temperature (NOCT). Table 11 gives a summary of Kyocera KC200GT nominal operation cell temperature data that have been provided in manufacturer's datasheet. Figures 9 and 10 show 


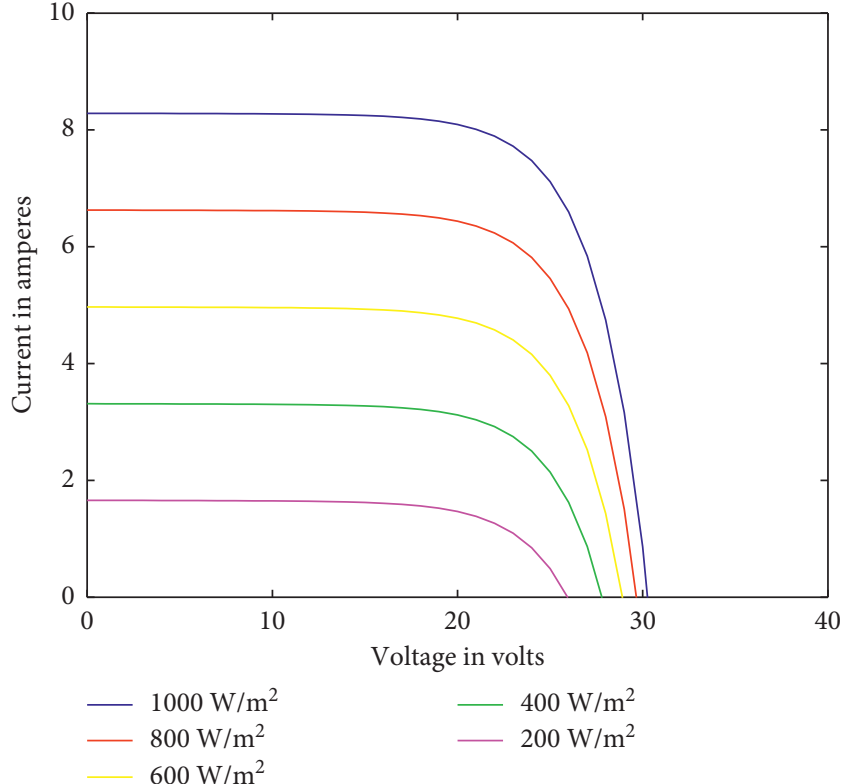

(a)

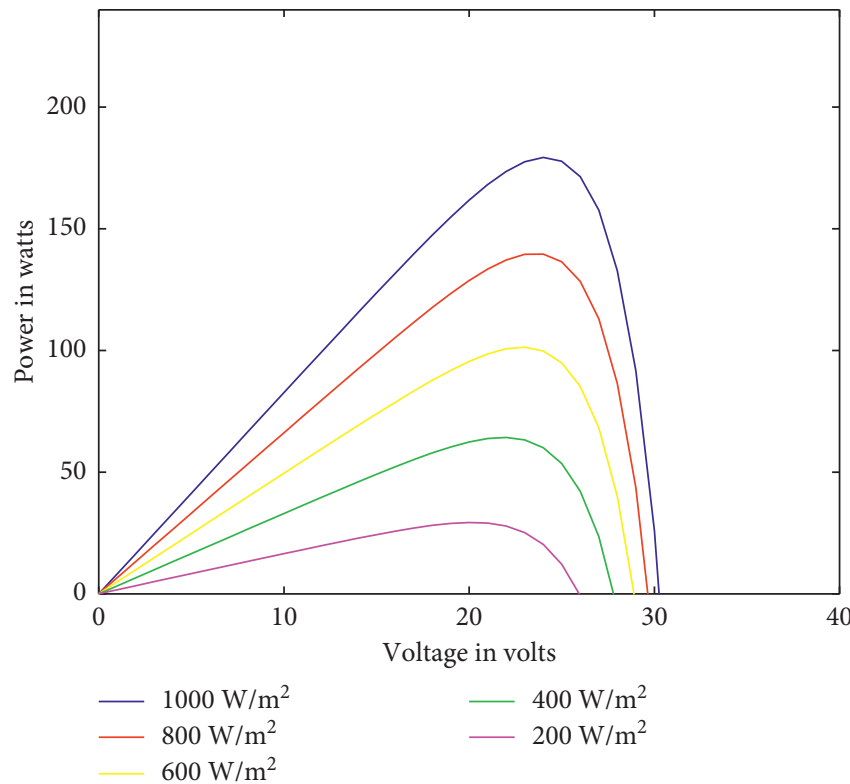

(b)

FigURE 10: IV and PV curves for KC200GT showing different irradiance values at $1000 \mathrm{~W} / \mathrm{m}^{2}, 800 \mathrm{~W} / \mathrm{m}^{2}, 600 \mathrm{~W} / \mathrm{m}^{2}, 400 \mathrm{~W} / \mathrm{m}^{2}$, and $200 \mathrm{~W} / \mathrm{m}^{2}$, for NOCT $=47^{\circ} \mathrm{C}$. (a) KC200GT IV curve for NOCT $=47^{\circ} \mathrm{C}$. (b) KC200GT PV curve for NOCT $=47^{\circ} \mathrm{C}$.

the IV and PV curves at both STC and NOCT for KC200GT. It is clear from the figures that the IV and PV characteristics coincide at a satisfactory level with the experimental data provided in the datasheet.

\section{Conclusion}

A new method has been developed and tested to determine the unknown parameters of a single-diode model for PV modules based on the datasheet values. This new algorithm provides a simplified and robust way of extracting $A, I_{o}, R_{\mathrm{sh}}, R_{s}$, and $I_{\mathrm{ph}}$ from the transcendental single-diode PV model equation using IV curve crucial points from the manufacturer's data. Further, these parameters have been used to plot the PV characteristics for the solar modules whose three critical points, $I_{\mathrm{sc}}, P_{\mathrm{mpp}}$, and $V_{\mathrm{oc}}$ match the datasheet values or data obtained through an experimental procedure. Various values of ideality factors near the optimum ideality factor offer different options of selecting the series and shunt resistance pairs that match the experimental data.

\section{Data Availability}

The simulation data used to support the findings of this study are included within the article and are available from the corresponding author upon request via ndegwarg@ uonbi.ac.ke.

\section{Conflicts of Interest}

The authors declare that they have no conflicts of interest.

\section{Acknowledgments}

The authors would like to thank the Department of Physics and the Board of Graduate School, Nairobi University (Kenya), for providing all the facilities and financial support, respectively, for this research.

\section{References}

[1] A. Orioli and A. Di Gangi, "A criterion for rating the usability and accuracy of the one-diode models for photovoltaic modules," Energies, vol. 9, no. 6, p. 427, 2016.

[2] V. Franzitta, A. Orioli, and A. Di Gangi, "Assessment of the usability and accuracy of the simplified one-diode models for photovoltaic modules," Energies, vol. 9, no. 12, p. 1019, 2016.

[3] V. Franzitta, A. Orioli, and A. D. Gangi, "Assessment of the usability and accuracy of two-diode models for photovoltaic modules," Energies, vol. 10, no. 4, p. 564, 2017.

[4] D. T. Cotfas, P. A. Cotfas, and S. Kaplanis, "Methods to determine the dc parameters of solar cells: a critical review," Renewable and Sustainable Energy Reviews, vol. 28, pp. 588596, 2013.

[5] V. J. Chin, Z. Salam, and K. Ishaque, "Cell modelling and model parameters estimation techniques for photovoltaic simulator application: a review," Applied Energy, vol. 154, pp. 500-519, 2015.

[6] A. M. Humada, M. Hojabri, S. Mekhilef, and H. M. Hamada, "Solar cell parameters extraction based on single and doublediode models: a review," Renewable and Sustainable Energy Reviews, vol. 56, pp. 494-509, 2016.

[7] A. R. Jordehi, "Parameter estimation of solar photovoltaic (PV) cells: a review," Renewable and Sustainable Energy Reviews, vol. 61, pp. 354-371, 2016.

[8] R. Abbassi, A. Abbassi, M. Jemli, and S. Chebbi, "Identification of unknown parameters of solar cell models: a 
comprehensive overview of available approaches," Renewable and Sustainable Energy Reviews, vol. 90, pp. 453-474, 2018.

[9] N. M. A. A. Shannan, N. Z. Yahaya, and B. Singh, "Singlediode model and two-diode model of PV modules: a comparison," in Proceedings of the 2013 IEEE International Conference on Control System, Computing and Engineering, IEEE, Penang, Malaysia, pp. 210-214, November 2013.

[10] A. Hovinen, "Fitting of the solar cell IV-curve to the two diode model," Physica Scripta, vol. T54, pp. 175-176, 1994.

[11] J. Gow and C. Manning, "Development of a model for photovoltaic arrays suitable for use in simulation studies of solar energy conversion systems," in Proceedings of the 6th International Conference on Power Electronics and Variable Speed Drives, pp. 69-74, Nottingham, UK, September 1996.

[12] L. Sandrolini, M. Artioli, and U. Reggiani, "Numerical method for the extraction of photovoltaic module doublediode model parameters through cluster analysis," Applied Energy, vol. 87, no. 2, pp. 442-451, 2010.

[13] C. Garrido-Alzar, "Algorithm for extraction of solar cell parameters from I-V curve using double exponential model," Renewable Energy, vol. 10, no. 2-3, pp. 125-128, 1997.

[14] M. Hejri, H. Mokhtari, M. R. Azizian, M. Ghandhari, and L. Soder, "On the parameter extraction of a five-parameter double-diode model of photovoltaic cells and modules," IEEE Journal of Photovoltaics, vol. 4, no. 3, pp. 915-923, 2014.

[15] K. Ishaque, Z. Salam, and H. Taheri, "Simple, fast and accurate two-diode model for photovoltaic modules," Solar Energy Materials and Solar Cells, vol. 95, no. 2, pp. 586-594, 2011.

[16] K. Kennerud, "Analysis of performance degradation in CdS solar cells," IEEE Transactions on Aerospace and Electronic Systems, vol. AES-5, no. 6, pp. 912-917, 1969.

[17] S. Shongwe and M. Hanif, "Comparative analysis of different single-diode PV modeling methods," IEEE Journal of Photovoltaics, vol. 5, no. 3, pp. 938-946, 2015.

[18] A. Ortiz-Conde, F. García-Sánchez, J. Muci, and A. SucreGonzález, "A review of diode and solar cell equivalent circuit model lumped parameter extraction procedures," Facta Universitatis-Series: Electronics and Energetics, vol. 27, no. 1, pp. 57-102, 2014.

[19] W. Xiao, W. G. Dunford, and A. Capel, “A novel modeling method for photovoltaic cells," in Proceedings of the 2004 IEEE 35th Annual Power Electronics Specialists Conference (IEEE Cat. No. 04CH37551), vol. 3, IEEE, Aachen, Germany, pp. 1950-1956, June 2004.

[20] E. Saloux, A. Teyssedou, and M. Sorin, "Explicit model of photovoltaic panels to determine voltages and currents at the maximum power point," Solar Energy, vol. 85, no. 5, pp. 713-722, 2011.

[21] Y. Mahmoud, W. Xiao, and H. Zeineldin, "A simple approach to modeling and simulation of photovoltaic modules," IEEE Transactions on Sustainable Energy, vol. 3, no. 1, pp. 185-186, 2011.

[22] C. Carrero, J. Rodríguez, D. Ramírez, and C. Platero, "Simple estimation of PV modules loss resistances for low error modelling," Renewable Energy, vol. 35, no. 5, pp. 1103-1108, 2010.

[23] E. Kiran and D. İnan, "Technical note an approximation to solar cell equation for determination of solar cell parameters," Renewable Energy, vol. 17, no. 2, pp. 235-241, 1999.

[24] R. Khezzar, M. Zereg, and A. Khezzar, "Modeling improvement of the four parameter model for photovoltaic modules," Solar Energy, vol. 110, pp. 452-462, 2014.

[25] N. Aoun and N. Bailek, "Evaluation of mathematical methods to characterize the electrical parameters of photovoltaic modules," Energy Conversion and Management, vol. 193, pp. 25-38, 2019.

[26] E. E. Van Dyk and E. L. Meyer, "Analysis of the effect of parasitic resistances on the performance of photovoltaic modules," Renewable Energy, vol. 29, no. 3, pp. 333-344, 2004.

[27] N. Dieme and M. Sane, "Impact of parasitic resistances on the output power of a parallel vertical junction silicon solar cell," Energy and Power Engineering, vol. 8, no. 3, pp. 130-136, 2016.

[28] S. Lineykin, M. Averbukh, and A. Kuperman, "Issues in modeling amorphous silicon photovoltaic modules by singlediode equivalent circuit," IEEE Transactions on Industrial Electronics, vol. 61, no. 12, pp. 6785-6793, 2014.

[29] S. Kabir, Basic Guidelines for Research: An Introductory Approach for All Disciplines, Book Zone Publication, Chawkbazar, India, 2016.

[30] E. I. Ortiz-Rivera and F. Z. Peng, "Analytical model for a photovoltaic module using the electrical characteristics provided by the manufacturer data sheet," in Proceedings of the 2005 IEEE 36th Power Electronics Specialists Conference, IEEE, Recife, Brazil, pp. 2087-2091, June 2005.

[31] S. R. Wenham, M. A. Green, M. E. Watt, R. Corkish, and A. Sproul, Applied Photovoltaics, Routledge, Abingdon, UK, 2013.

[32] S. Manda, P. Chaubey, S. Yelisetti, S. K. Kuralla, N. k. Yadav, and N. K. Meena, "Exact parameter identification of photovoltaic panel by using datasheet details," Energy Procedia, vol. 158, pp. 972-977, 2019.

[33] T. Easwarakhanthan, J. Bottin, I. Bouhouch, and C. Boutrit, "Nonlinear minimization algorithm for determining the solar cell parameters with microcomputers," International Journal of Solar Energy, vol. 4, no. 1, pp. 1-12, 1986.

[34] W. De Soto, S. A. Klein, and W. A. Beckman, "Improvement and validation of a model for photovoltaic array performance," Solar Energy, vol. 80, no. 1, pp. 78-88, 2006.

[35] Z. Z. Zhang, X. F. Cheng, and J. L. Liu, "An improvement method for extracting five parameters of a solar cell based on Lambert W-function with the current-voltage data," in Applied Mechanics and Materials, vol. 291, pp. 38-42, Trans Tech Publications, Stafa-Zurich, Switzerland, 2013.

[36] E. I. Batzelis and S. A. Papathanassiou, "A method for the analytical extraction of the single-diode PV model parameters," IEEE Transactions on Sustainable Energy, vol. 7, no. 2, pp. 504-512, 2015.

[37] X. Feng, X. Qing, C. Chung, H. Qiao, X. Wang, and X. Zhao, "A simple parameter estimation approach to modeling of photovoltaic modules based on datasheet values," Journal of Solar Energy Engineering, vol. 138, no. 5, Article ID 051010, 2016.

[38] D. Sera, R. Teodorescu, and P. Rodriguez, "PV panel model based on datasheet values," in Proceedings of the 2007 IEEE International Symposium on Industrial Electronics, IEEE, Vigo, Spain, pp. 2392-2396, June 2007.

[39] A. Yahfdhou, A. K. Mahmoud, and I. Youm, "Evaluation and determination of seven and five parameters of a photovoltaic generator by an iterative method," 2016, https://arxiv.org/ftp/ arxiv/papers/1601/1601.03257.pdf.

[40] C. Saha, N. Agbu, and R. Jinks, "Review article of the solar PV parameters estimation using evolutionary algorithms," MOJ Solar and Photoenergy Systems, vol. 2, no. 2, pp. 66-78, 2018.

[41] M. R. AlRashidi, M. F. AlHajri, K. M. El-Naggar, and A. K. AlOthman, "A new estimation approach for determining the I-V characteristics of solar cells," Solar Energy, vol. 85, no. 7, pp. 1543-1550, 2011. 
[42] M. Zagrouba, A. Sellami, M. Bouaïcha, and M. Ksouri, "Identification of PV solar cells and modules parameters using the genetic algorithms: application to maximum power extraction," Solar Energy, vol. 84, no. 5, pp. 860-866, 2010.

[43] K. M. El-Naggar, M. R. AlRashidi, M. F. AlHajri, and A. K. AlOthman, "Simulated annealing algorithm for photovoltaic parameters identification," Solar Energy, vol. 86, no. 1, pp. 266-274, 2012.

[44] F. Dkhichi, B. Oukarfi, A. Fakkar, and N. Belbounaguia, "Parameter identification of solar cell model using LevenbergMarquardt algorithm combined with simulated annealing," Solar Energy, vol. 110, pp. 781-788, 2014.

[45] M. Ye, X. Wang, and Y. Xu, "Parameter extraction of solar cells using particle swarm optimization," Journal of Applied Physics, vol. 105, no. 9, Article ID 094502, 2009.

[46] M. Azab, "Parameters estimation of PV modules without experimental measurements using particle swarm optimization," in Proceedings of the IEEE Industrial Electronics Conference IECON'13, pp. 7004-7008, Vienna, Austria, November 2013.

[47] W. Han, H.-H. Wang, and L. Chen, "Parameters identification for photovoltaic module based on an improved artificial fish swarm algorithm," The Scientific World Journal, vol. 2014, Article ID 859239, 12 pages, 2014.

[48] H. Al-Hamadi, "Fuzzy estimation analysis of photovoltaic model parameters," Journal of Power and Energy Engineering, vol. 3, no. 7, pp. 39-43, 2015.

[49] A. Kulaksız, "ANFIS-based parameter estimation of one-diode equivalent circuit model of PV modules," in Proceedings of the 2011 IEEE 12th International Symposium on Computational Intelligence and Informatics (CINTI), IEEE, Budapest, Hungary, pp. 415-420, November 2011.

[50] M. Karamirad, M. Omid, R. Alimardani, H. Mousazadeh, and S. N. Heidari, "ANN based simulation and experimental verification of analytical four- and five-parameters models of PV modules," Simulation Modelling Practice and Theory, vol. 34, pp. 86-98, 2013.

[51] F. Salem and M. A. Awadallah, "Parameters estimation of photovoltaic modules: comparison of ANN and ANFIS," International Journal of Industrial Electronics and Drives, vol. 1, no. 2, pp. 121-129, 2014.

[52] M. Hejri, H. Mokhtari, M. R. Azizian, and L. Söder, “An analytical-numerical approach for parameter determination of a five-parameter single-diode model of photovoltaic cells and modules," International Journal of Sustainable Energy, vol. 35, no. 4, pp. 396-410, 2013.

[53] T. R. Ayodele, A. S. O. Ogunjuyigbe, and E. E. Ekoh, "Evaluation of numerical algorithms used in extracting the parameters of a single-diode photovoltaic model," Sustainable Energy Technologies and Assessments, vol. 13, pp. 51-59, 2016.

[54] R. A. P. Franco and F. H. T. Vieira, "Analytical method for extraction of the single-diode model parameters for photovoltaic panels from datasheet data," Electronics Letters, vol. 54, no. 8, pp. 519-521, 2018.

[55] M. G. Villalva, J. R. Gazoli, and E. R. Filho, "Comprehensive approach to modeling and simulation of photovoltaic arrays," IEEE Transactions on Power Electronics, vol. 24, no. 5, pp. 1198-1208, 2009.

[56] M. Bashahu and P. Nkundabakura, "Review and tests of methods for the determination of the solar cell junction ideality factors," Solar Energy, vol. 81, no. 7, pp. 856-863, 2007.

[57] C. Carrero, D. Ramírez, J. Rodríguez, and C. A. Platero, "Accurate and fast convergence method for parameter estimation of PV generators based on three main points of the I-V curve," Renewable Energy, vol. 36, no. 11, pp. 2972-2977, 2011.

[58] J. Cubas, S. Pindado, and A. Farrahi, "New method for analytical photovoltaic parameter extraction," in Proceedings of the 2013 International Conference On Renewable Energy Research And Applications (ICRERA), IEEE, Madrid. Spain, pp. 873-877, October 2013.

[59] M. Zaimi, H. El Achouby, A. Ibral, and E. M. Assaid, "Determining combined effects of solar radiation and panel junction temperature on all model-parameters to forecast peak power and photovoltaic yield of solar panel under nonstandard conditions," Solar Energy, vol. 191, pp. 341-359, 2019.

[60] W. Shen, Y. Ding, F. H. Choo, P. Wang, P. C. Loh, and K. K. Tan, "Mathematical model of a solar module for energy yield simulation in photovoltaic systems," in Proceedings of the International Conference on Power Electronics and Drive Systems (PEDS), IEEE, Taipei, Taiwan, pp. 336-341, November 2009.

[61] B. K. Atay and U. Eminoğlu, "A new approach for parameter estimation of the single-diode model for photovoltaic cells/ modules," Turkish Journal of Electrical Engineering \& Computer Sciences, vol. 27, no. 4, pp. 3026-3039, 2019.

[62] H. S. Rauschenbach, "Electrical output of shadowed solar arrays," IEEE Transactions on Electron Devices, vol. 18, no. 8, pp. $483-490,1971$.

[63] L. Castaner and S. Silvestre, Modelling Photovoltaic Systems Using PSpice, John Wiley \& Sons, Hoboken, NJ, USA, 2002.

[64] R. C. Neville, Solar Energy Conversion: The Solar Cell, Elsevier, Amsterdam, Netherlands, 1995.

[65] R. Chenni, M. Makhlouf, T. Kerbache, and A. Bouzid, "A detailed modeling method for photovoltaic cells," Energy, vol. 32, no. 9, pp. 1724-1730, 2007.

[66] H. El Achouby, M. Zaimi, A. Ibral, and E. M. Assaid, "New analytical approach for modelling effects of temperature and irradiance on physical parameters of photovoltaic solar module," Energy Conversion and Management, vol. 177, pp. 258-271, 2018

[67] J. C. H. Phang, D. S. H. Chan, and J. R. Phillips, “Accurate analytical method for the extraction of solar cell model parameters," Electronics Letters, vol. 20, no. 10, pp. 406-408, 1984.

[68] L. Reis, J. Camacho, and D. Novacki, “The Newton raphson method in the extraction of parameters of PV modules," in Proceedings of the International Conference on Renewable Energies and Power Quality (ICREPQ'17), pp. 4-6, Malaga, Spain, 2017.

[69] D. S. H. Chan and J. C. H. Phang, "Analytical methods for the extraction of solar-cell single- and double-diode model parameters from I-V characteristics," IEEE Transactions on Electron Devices, vol. 34, no. 2, pp. 286-293, 1987.

[70] A. A. El Tayyan, "An approach to extract the parameters of solar cells from their illuminated I-V curves using the Lambert W function," Turkish Journal of Physics, vol. 39, no. 1, pp. 1-15, 2015.

[71] A. Laudani, F. Riganti Fulginei, and A. Salvini, "Identification of the one-diode model for photovoltaic modules from datasheet values," Solar Energy, vol. 108, pp. 432-446, 2014.

[72] A. Hussein and A. Hussein, "A simple approach to extract the unknown parameters of PV modules," Turkish Journal of Electrical Engineering \& Computer Sciences, vol. 25, no. 5, pp. 4431-4444, 2017. 
[73] V. Jha and U. S. Triar, "A novel approach for evaluation of parameters of photovoltaic modules," International Journal of Applied Engineering Research, vol. 12, no. 21, pp. 1116711178, 2017. 